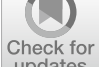

Check for

Cite as

Nano-Micro Lett.

(2020) 12:21

Received: 7 October 2019

Accepted: 20 November 2019

Published online: 13 January 2020

(C) The Author(s) 2020

\section{Single-Atom Catalysts for Electrochemical Hydrogen Evolution Reaction: Recent Advances and Future Perspectives}

\author{
Zonghua $\mathrm{Pu}^{1,2}$, Ibrahim Saana Amiinu ${ }^{2}$, Ruilin Cheng ${ }^{2}$, Pengyan $\mathrm{Wang}^{2}$,
} Chengtian Zhang ${ }^{2}$, Shichun $\mathrm{Mu}^{2} \bowtie$, Weiyue Zhao ${ }^{3}$, Fengmei $\mathrm{Su}^{4}$, Gaixia Zhang ${ }^{1 凶}$, Shijun Liao ${ }^{3}$, Shuhui Sun $^{1 凶}$

$\bowtie$ Shichun Mu,msc@whut.edu.cn; Gaixia Zhang, gaixia.zhang@emt.inrs.ca; Shijun Liao, chsjliao@scut.edu.cn; Shuhui Sun, shuhui@emt.inrs.ca

1 Institut National de la Recherche Scientifique-Énergie Matériaux et Télécommunications, Varennes, QC J3X 1S2, Canada

2 State Key Laboratory of Advanced Technology for Materials Synthesis and Processing, Wuhan University of Technology, Wuhan 430070, People's Republic of China

3 The Key Laboratory of Fuel Cell Technology of Guangdong Province, The Key Laboratory of New Energy Technology of Guangdong Universities, School of Chemistry and Chemical Engineering, South China University of Technology, Guangzhou 510641, People's Republic of China

4 Key Laboratory of Materials Processing and Mold, Ministry of Education, Zhengzhou University, Zhengzhou 450002, People's Republic of China

\title{
HIGHLIGHTS
}

- All the important single-atom catalysts (SACs) synthetic strategies, such as wet-chemistry method, atomic layer deposition, metalorganic framework-derived method, electrodeposition, high-temperature atom trapping from bulk particles, and vacancies/defects immobilized strategy, have been summarized and discussed in detail.

- Various metal-based (especially Pt, Pd, Ru, Fe, Co, Ni, Mo, W, V) SACs in electrocatalytic hydrogen evolution reaction (HER) have been systematically reviewed.

- The current key challenges in SACs for electrochemical HER are pointed out, and some potential strategies/perspectives are proposed.

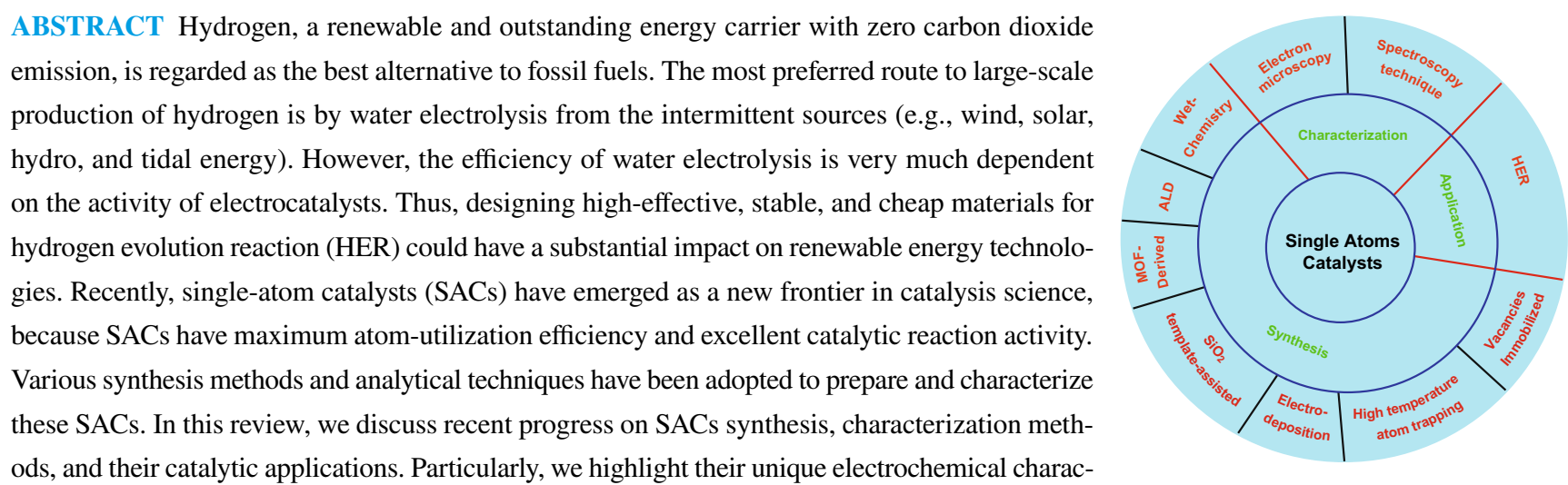
teristics toward HER. Finally, the current key challenges in SACs for HER are pointed out and some potential directions are proposed as well.

KEYWORDS Single-atom catalysts; Nanomaterials; Electrocatalyst; Hydrogen evolution reaction; Electrochemical energy conversion 


\section{Introduction}

With the depletion of fossil fuels (coal, oil, and natural gas), heavily environmental pollution, and climate change, the exploitation of safe, clean, efficient, sustainable, and environmental-friendly energy sources has become a major societal and technological pursuit in the twenty-first century [1-7]. Hydrogen is considered as a viable substitute for fossil fuels in the future because of its renewability, zero carbon dioxide emission, and high mass-specific energy density [8-12]. Among the hydrogen production method, water electrolysis is an attractive way due to its device simplicity, high product purity, and renewability [13-17]. The process of water electrolysis is based upon two half-reactions: one reaction is oxygen evolution reaction (OER), and the other reaction is hydrogen evolution reaction (HER) [18-28]. Although water electrolysis has received much attention, the implementation of efficient water splitting technology is still a huge challenge due to the kinetic barrier of both reactions. In fact, both HER and OER suffer from high overpotentials or low Faradic yields for electrodes which lead to low energy utilization [29-40]. In order to overcome these problems, appropriate catalysts are needed to improve electrode efficiency by decreasing the activation energy and increasing the conversion efficiency. In other words, catalysts materials play an important role in improving the performance of both HER and OER. Currently, Pt group electrocatalysts are regarded as the benchmark for HER because they exhibit excellent activity over the $\mathrm{pH}$ range from 0 to 14 [41-53]. Nevertheless, the high cost, poor stability, and the low availability of noble metal limit their wide applications. Therefore, it is highly urgent to develop low-cost, highly active, and sustainable electrocatalytic materials for HER. For this purpose, extensive efforts have been devoted to preparing low-Pt even non-Pt-based electrocatalytic materials [54-72].

Single-atom catalysts (SACs), with only isolated single-atom dispersion on the support surface, have attracted extensive attention in many kinds of catalysis community recently due to their maximum atom-utilization efficiency, high selectivity, and unique properties [73-80]. The first reported SACs by Zhang's groups occurred in 2011 where a coprecipitation method was employed to synthesize $\mathrm{Pt}$ SACs on iron oxide substrate $\left(\mathrm{Pt}_{1} / \mathrm{FeO}_{x}\right)$, showing high performance and durability toward the $\mathrm{CO}$ oxidation [74]. Compared with other heterogeneous materials, SACs not only possess homogenized active species for catalytic reactions which are similar to homogeneous materials, but also have extra advantages of high reusability and durability that originate from heterogeneous materials. Therefore, SACs have great advantages [73, 81-86]. Given this unique characteristic, SACs have attracted extensive attention in various kinds of catalytic applications, including HER, OER, organic catalytic reaction, oxygen reduction reaction (ORR), $\mathrm{N}_{2}$ reduction reaction (NRR), $\mathrm{CO}_{2}$ reduction reaction $\left(\mathrm{CO}_{2} \mathrm{RR}\right)$, and other important reactions [74, 87-123]. In addition, advanced characterization techniques including scanning tunneling microscope (STM), aberration-corrected high-angle annular dark-field scanning transmission electron microscopy (AC-HAADFSTEM), synchrotron-radiated X-ray absorption fine structure (XAFS) spectroscopy, etc., are widely adopted for the characterization of SACs, which can directly measure the single atom to confirm the structure and electronic properties of SACs including a confirmation of the single metal atom, the chemical state of the metal center, and the coordination environment [121, 124]. Furthermore, density functional theory (DFT) simulation has brought unprecedented to discovering catalytic reaction mechanisms, enabling the rational design of materials with tailored activity.

In this review, we focus on SACs toward HER, with a much more comprehensive and detailed introduction and discussions. We first highlight several novel synthetic methods, especially the atomic layer deposition (ALD), the metal-organic framework (MOF)-derived strategy, and vacancies/defects immobilized methodology, for SACs synthesis. Next, to reveal the structures and compositions of SACs, different characterization techniques, such as XAFS spectroscopy, AC-HAADF-STEM techniques, and DFT simulation, have been summarized and discussed. In addition, $\mathrm{Pt}, \mathrm{Pd}, \mathrm{Ru}, \mathrm{Fe}, \mathrm{Co}, \mathrm{Ni}, \mathrm{Mo}, \mathrm{W}$, V, etc., metalbased SACs in electrocatalytic HER have been systematically reviewed. Finally, the current key challenges in SACs for electrochemical HER are pointed out and some potential strategies/perspectives are proposed as well. Thus, this review covers the key aspects of SACs for hydrogen production via HER, including key synthesis strategies, evidence-based characterizations, and impact in the field of hydrogen production. We believe it is of great importance and interest to the development of SACs toward the 
application of HER, and it can be extended to other fields as well.

\section{Synthetic Strategies}

In general, it is still a huge challenge to prepare SACs with robust structures and high performance due to its aggregation tendency. Fortunately, technological advances have evolved with effective methods to overcome such difficulties. In this rapidly developing area, some methods have been exploited for constructing SACs, including the wetchemistry method, ALD, MOF-derived method, $\mathrm{SiO}_{2}$ template-assisted pyrolysis method, electrodeposition approach, high-temperature atom trapping method, vacancies/defects immobilized strategy, photochemical reduction, iced photochemical reduction, chemical reduction, hydrothermal reduction methods, and ambient synthetic strategy [52, 53, $74,93,125-127]$. In addition, some advantages and disadvantages of these synthesis strategies for preparing SACs are listed in Table 1.

\subsection{Wet-Chemistry Strategies}

Generally, the wet-chemistry routes to prepare SACs involve three steps. The first involves the introduction of the metal species on various supports via impregnation and coprecipitation. The second concerns drying and annealing, and the third is by reduction or activation [73]. In theory, SACs can be obtained by reducing the metal species loading to a fairly low level. However, on the one hand, in most catalytic reactions, more accessible catalytic active species are required. On the other hand, along with the reduced metal, the smaller particle size can also result in increased surface energy, thereby making the metal atoms easily aggregate into larger particles. Therefore, for the wet-chemistry approach, SACs require to be effectively embedded in the support in order to avoid aggregation of the metal atoms into metal nanoclusters or even large nanoparticles [121].

The wet-chemistry strategy has been recognized as an effective method for the synthesis of metal single atoms supported on various oxide substrates. An added advantage of this method is that no specialized equipment is needed. Additionally, it is also the preferred method for potential large-scale production of supported metal catalysts. However, the wet-chemistry strategy has obvious disadvantages of preparing high metal loading materials [128]. For example, Zhang's group successfully developed Pt SACs supported on $\mathrm{FeO}_{x}\left(\mathrm{Pt}_{1} / \mathrm{FeO}_{x}\right)$ by the coprecipitation method with a Pt loading only $\sim 0.18 \mathrm{wt} \%$. The HAADF-STEM images of $\mathrm{Pt}_{1} / \mathrm{FeO}_{x}$ further confirm the presence of $\mathrm{Pt}$ single atoms (Fig. 1a-d). In addition, DFT simulation (Fig. 1e) indicates that the most probable sites for Pt SACs are located on the $\mathrm{O}_{3}$-terminated surface. In other words, each Pt single atom is coordinated with three surface $\mathrm{O}$ atoms [77]. To date, all kinds of oxides substrate such as $\mathrm{FeO}_{x}, \mathrm{TiO}_{2}, \mathrm{CeO}_{2}$, $\mathrm{Al}_{2} \mathrm{O}_{3}$, and $\mathrm{ZnO}$ have been investigated as support materials for SACs of Pt, Ir, Rh, Au, and Pd [74, 129-134]. Such catalysts have displayed high catalytic performance toward the water-gas shift reaction, $\mathrm{CO}$ oxidation, and selective organic conversion reactions.

Table 1 Partial list of synthesis strategies for producing SACs

\begin{tabular}{|c|c|c|c|}
\hline Synthetic method & Advantage & Disadvantage & References \\
\hline Wet-chemistry method & Simply equipment; easily large-scale production & Low metal loading & {$[74,123,129]$} \\
\hline ALD & Precise control SACs on different substrates & Low yields; high equipment cost & {$[52,137,139]$} \\
\hline MOF-derived method & Easily introduce heteroatoms to anchoring metal atoms & High synthesis temperature & {$[39,103,150-152]$} \\
\hline $\mathrm{SiO}_{2}$ template-assisted pyrolysis & Potential large-scale production & Dangerous etching reagent (HF) & {$[107,148,149]$} \\
\hline Electrodeposition & $\begin{array}{l}\text { Controllable amount and size; generally deposited on } \\
\text { the outermost surface; facile }\end{array}$ & Non-uniform plating & {$[53,93]$} \\
\hline $\begin{array}{l}\text { High-temperature atom trapping } \\
\text { from bulk particles }\end{array}$ & Potential large-scale production & High synthesis temperature & [156-159] \\
\hline Vacancies/defects immobilized & Easily capture or anchor metal species & Non-stability of the defects & [161-163] \\
\hline Iced photochemical reduction & Tuning the solid nucleation & A sluggish nucleation rate & {$[125]$} \\
\hline Ambient synthetic strategy & Eco-friendly; low cost; mass production of SACs & Non-general method & [127] \\
\hline
\end{tabular}




\subsection{Atomic Layer Deposition Method}

In general, the ALD technique has been used to prepare metal oxide thin films with atomically precise control [135, 136]. In 2013, the ALD technique was adopted to fabricate Pt SACs for the first time by Sun's group [137]. As illustrated in Fig. 2a, the implanted oxygen atoms on the surface of graphene nanosheets can react with (methylcyclopentadienyl) trimethylplatinum $\left(\mathrm{MeCpPtMe}_{3}\right)$, in which some of the organic linkers are converted into $\mathrm{H}_{2} \mathrm{O}$, $\mathrm{CO}_{2}$, and hydrocarbon fragments, leading to the formation of Pt-containing monolayers. Next, the Pt-containing monolayer reacts with subsequent $\mathrm{O}_{2}$ to form a new absorbed oxygen layer on the Pt surface. This two-step process forms a whole ALD cycle. The morphology, size, and loading weight of Pt SACs can be adjusted by changing the number of ALD cycles (Fig. 2b-g). Using a similar method, Cheng and coworkers also prepared Pt SACs on the nitrogen-doped graphene (Fig. 2h). As shown in Fig. 2i, j, the size and loading density of the Pt catalyst can be well adjusted through changing the ALD cycles. More importantly, the obtained N-doped graphene nanosheetssupported Pt SACs exhibit excellent HER catalytic activity [52]. Although using the ALD method, some noble metal $\mathrm{Ru}, \mathrm{Pt}$, and Pd SACs can be successfully grown on several types of substrates, such as $\mathrm{SiO}_{2}, \mathrm{Al}_{2} \mathrm{O}_{3}$, and $\mathrm{TiO}_{2}$ [52, 137-140]. It still suffers from low yields, high cost of equipment, and precursors, which is not favorable for widespread production [141-143].

\subsection{MOF-Derived Method}

Metal-organic frameworks (MOFs), due to their high specific surface area, tunable porosity, and unique structures, have attracted enormous attention for many applications including catalysis, sensing, separation, and gas adsorption [144-147]. Researchers have obtained different functional MOFs by changing the metal ions and organic precursors. Very recently, a series of single atoms of $\mathrm{Co}, \mathrm{Fe}, \mathrm{Ni}$, and $\mathrm{W}$ anchored on nitrogen-doped carbon frameworks have been fabricated by pyrolysis MOFs [39, 89, 148, 149]. Li and coworkers first reported that single Co atoms can be obtained by pyrolysis $\mathrm{Zn} / \mathrm{Co}$ bimetallic zeolitic imidazolate framework (ZIF). Figure 3a illustrates the formation mechanism
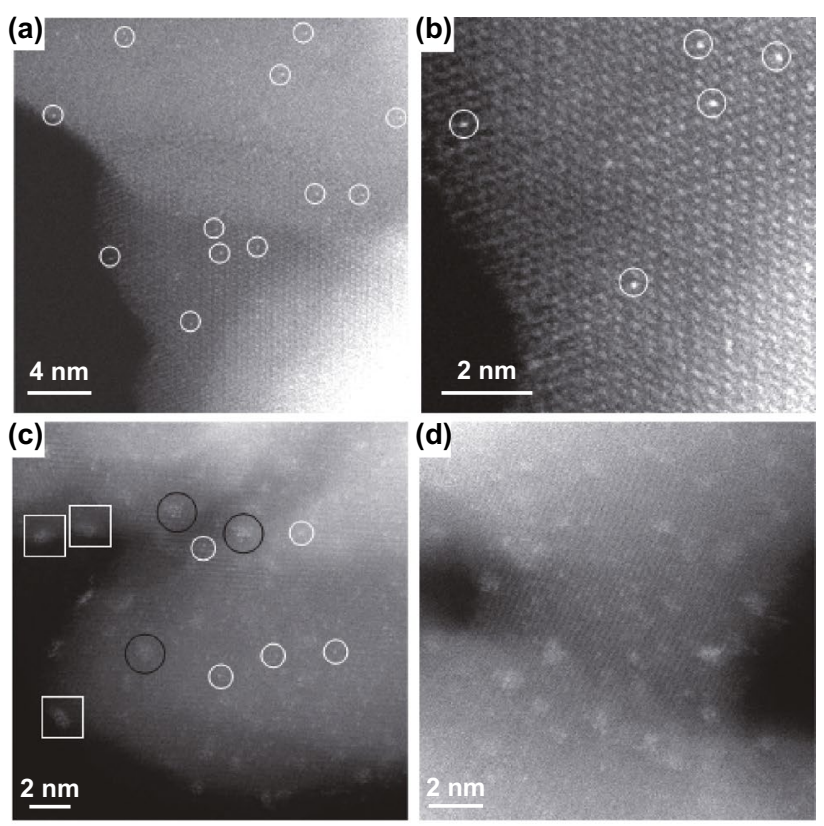

(e)

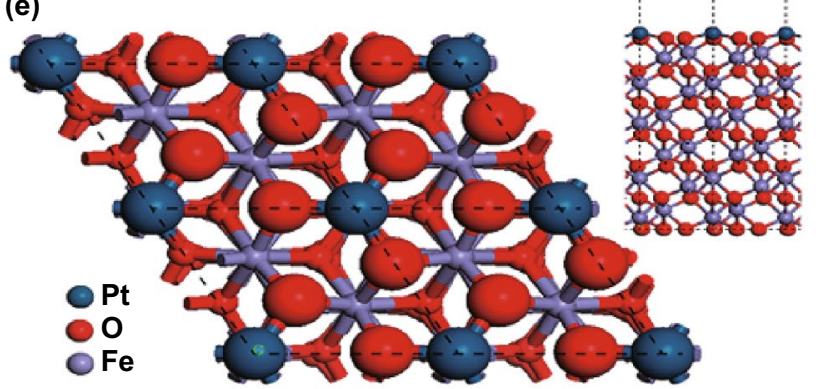

Fig. 1 a Pt SACs are uniformly distributed on the $\mathrm{FeO}_{x}$ and $\mathbf{b}$ directly occupy the positions of the Fe atoms. c, $\mathbf{d}$ A mixture of SACs (in white circles), 2D Pt rafts consisting of less than ten $\mathrm{Pt}$ atoms (in black circles) and the size of 3D Pt clusters about $1 \mathrm{~nm}$ or less (white squares) are seen clearly. e DFT model of $\mathrm{Pt}_{1} / \mathrm{FeO}_{x}$. a-e Reproduced from Ref. [77] with permission. Copyright 2011 Nature Publishing Group

of Co SAs/N-C. During annealing, the $\mathrm{Zn} / \mathrm{Co}$ bimetallic $\mathrm{ZIF}$ and the organic precursors of ZIFs are transformed into nitrogen-doped porous carbon (N-C). Subsequently, the $\mathrm{Zn}$ and $\mathrm{Co}$ ions are reduced by the $\mathrm{N}-\mathrm{C}$. Pre-meditated mixing of $\mathrm{Zn}$ can not only change the distance of adjacent $\mathrm{Co}$ atoms and provide $\mathrm{N}$-rich centers, but also avoid the formation of Co-Co bonds under the high temperatures $\left(\sim 900^{\circ} \mathrm{C}\right)$. Finally, the Co single atoms (Co SAs) anchored on the $\mathrm{N}-\mathrm{C}$ can be obtained after evaporation of low boiling point $\mathrm{Zn}$ atoms [39]. The HAADF-STEM images of the obtained Co SAs/N-C are illustrated in Fig. 3b-d. Electron energy loss spectrum (EELS) and X-ray absorption spectroscopy 


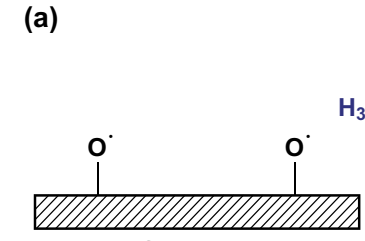

Graphene

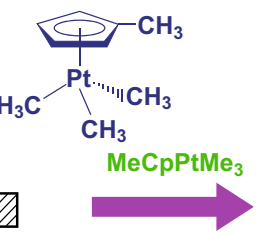

$\mathrm{MeCpPtMe}_{3}$

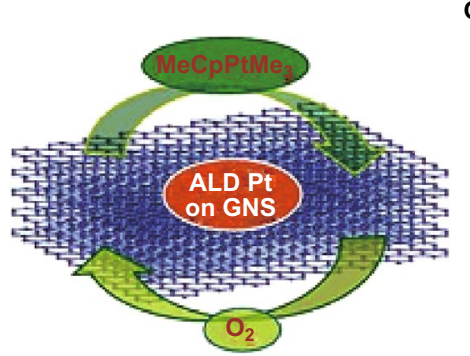

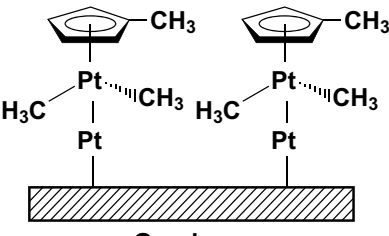

Graphene

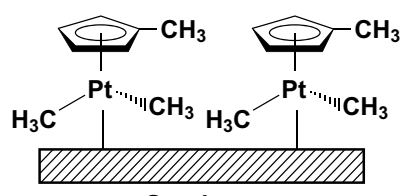

Graphene
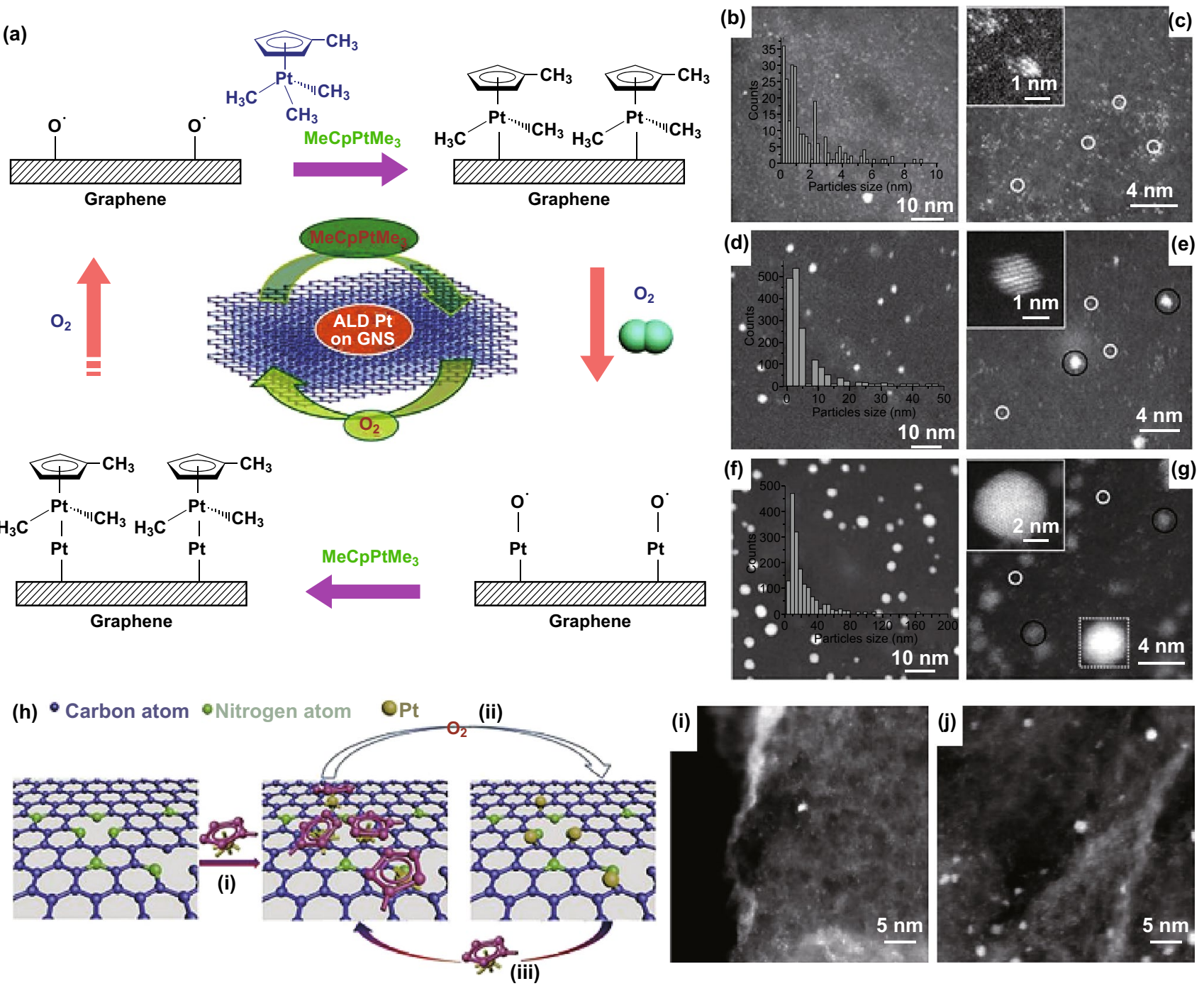

Fig. 2 a Schematic illustrations of Pt ALD mechanism on graphene nanosheets. b-g Present the results with (b, c) 50 , (d, e) 100 , and (f, $\mathbf{g}) 150$ ALD cycles. $\mathbf{h}$ Schematic illustration of the Pt ALD mechanism on NGNs. HAADF-STEM images of ALDPt/NGNs samples with $\mathbf{i} 50$ and $\mathbf{j} 100$ ALD cycles. a-g Reproduced from Refs. [137, 52] with permission. Copyright 2013 and 2016 Nature Publishing Group

(XAS) characterization further confirm the formation of $\mathrm{Co}-\mathrm{N}_{4}$ structure. Interestingly, such $\mathrm{Co}-\mathrm{N}_{4}$ structure shows outstanding ORR catalytic activity with a $0.88 \mathrm{~V}$ half-wave potential (Fig. 3e). Similarly, Fe-Co dual SACs anchored on $\mathrm{N}-\mathrm{C}$ have also been prepared by pyrolysis $\mathrm{Fe} / \mathrm{Co}$ bimetallic ZIF (Fig. 3f-i) [150]. Additionally, the coordination number of Co SAs can be well adjusted by varying the pyrolysis temperature of $\mathrm{Zn} / \mathrm{Co}$ bimetallic ZIF. For example, different Co-N coordination numbers of $\mathrm{Co}-\mathrm{N}_{2}, \mathrm{Co}-\mathrm{N}_{3}$, and $\mathrm{Co}-\mathrm{N}_{4}$ can be selectively prepared at different pyrolysis temperatures $\left(1000,900\right.$, and $\left.800{ }^{\circ} \mathrm{C}\right)(\mathrm{Fig} .3 \mathrm{j}, \mathrm{k})$. These $\mathrm{Co}-\mathrm{N}_{2}$, $\mathrm{Co}-\mathrm{N}_{3}$, and $\mathrm{Co}-\mathrm{N}_{4}$ structures have been also applied as effective $\mathrm{CO}_{2} \mathrm{RR}$ catalysts. As exhibited by the polarization curves in Fig. 31, Co- $\mathrm{N}_{2}$ achieves the excellent catalytic activity toward $\mathrm{CO}_{2} \mathrm{RR}$ [147].

The molecular-scale cavities within MOFs are usually interconnected by pores. Thus, metal species with an appropriate size can be encapsulated and separated in the cages. For example, $\mathrm{Fe}(\mathrm{acac})_{3}$ has a molecular diameter of ca. 9.7 $\AA$, larger than the pore size $(3.4 \AA$ ) but lower than the cavity diameter (11.6 $\AA$ ) of ZIF-8. When ZIF-8 is mixed with the $\mathrm{Fe}(\mathrm{acac})_{3}$ molecules, the $\mathrm{Fe}(\mathrm{acac})_{3}$ molecules can be encapsulated by the ZIF- 8 cages. After the pyrolysis of the confined $\mathrm{Fe}(\mathrm{acac})_{3}, \mathrm{ZIF}-8$ is converted to $\mathrm{N}-\mathrm{C}$. At the same 

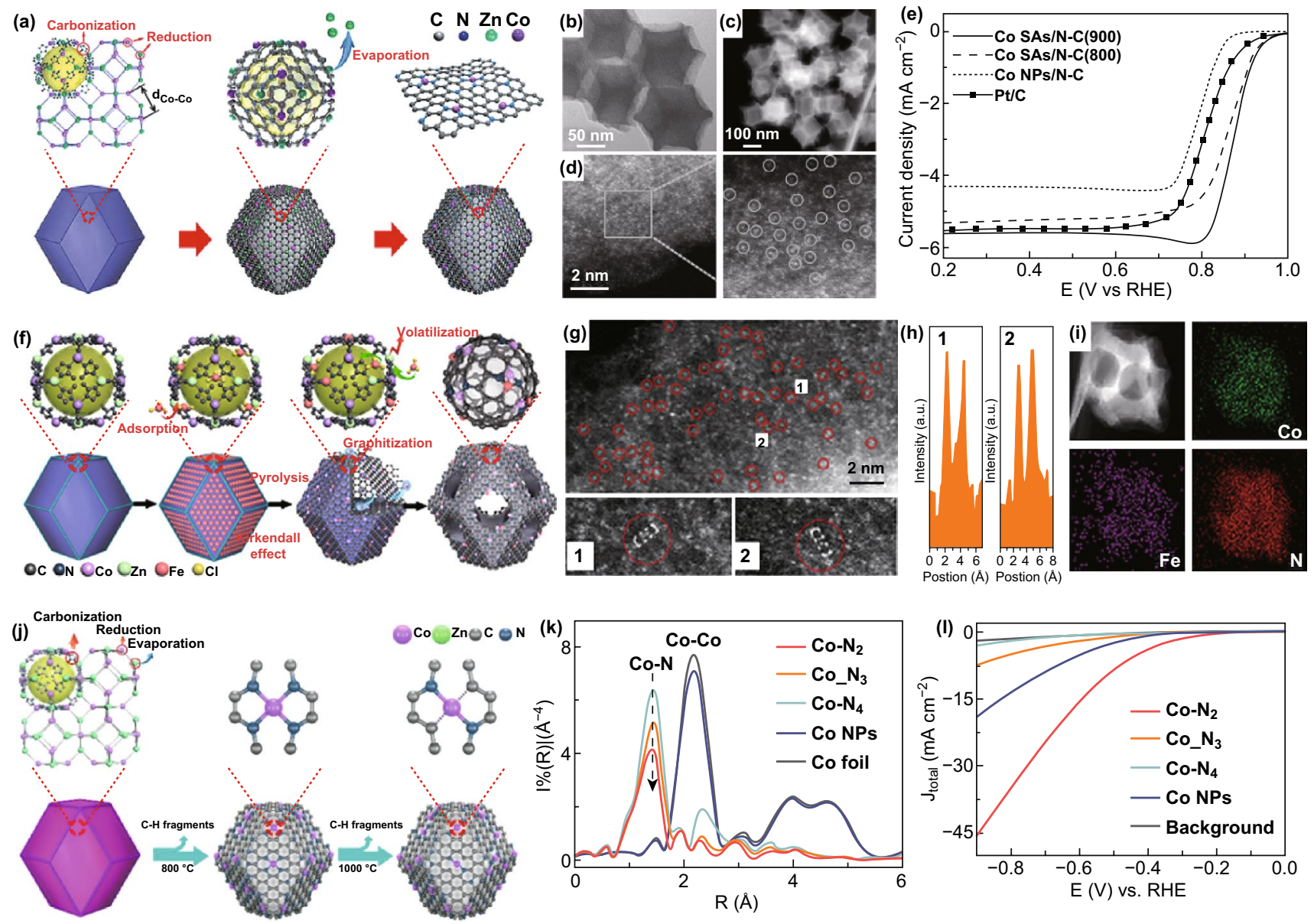

Fig. 3 a The schematic illustrations of Co SAs/N-C. b TEM, c, d HAADF-STEM images of Co SAs/N-C(800). e LSV of Co SAs/N-C, Co NPs-N/C, and Pt/C in $\mathrm{O}_{2}$-saturated $0.1 \mathrm{M} \mathrm{KOH}$ solutions. f Preparation of $(\mathrm{Fe}, \mathrm{Co}) / \mathrm{N}-\mathrm{C}$. g HAADF-STEM of (Fe, Co)/N-C. h Corresponding intensity profiles obtained on the zoomed areas in $\mathbf{g}$. i Corresponding EELS mapping of Co, Fe, and N. j Schematic formation process of Co-N and $\mathrm{Co}-\mathrm{N}_{2}$. $\mathrm{k}$ EXAFS spectra confirm the atomic dispersion of Co atoms in $\mathrm{Co}-\mathrm{N}_{2}, \mathrm{Co}-\mathrm{N}_{3}$ and $\mathrm{Co}-\mathrm{N}_{4}$. 1 LSVs of Co-N $\mathrm{N}_{2}, \mathrm{Co}-\mathrm{N}_{3}, \mathrm{Co}-\mathrm{N}_{4}$ and Co NPs. a-e and j-l Reproduced from Refs. [102, 147] with permission. Copyright 2016 and 2017 Wiley-VCH. f-i Reproduced from Ref. [150] with permission. Copyright 2017 American Chemical Society

time, $\mathrm{Fe}(\mathrm{acac})_{3}$ is reduced by the generated $\mathrm{N}-\mathrm{C}$, leading to the formation of Fe SACs on the N-C [103]. Replacement of $\mathrm{Fe}(\mathrm{acac})_{3}$ with $\mathrm{Ru}_{3}(\mathrm{CO})_{12}$ produces isolated $\mathrm{Ru}_{3}$ clusters embedded on $\mathrm{N}-\mathrm{C}$ by the same synthesis strategy [151]. In 2018, Cheng et al. [148] reported a novel strategy to construct W SACs on $\mathrm{N}-\mathrm{C}$ via using MOFs as the precursor. It can be noticed that the uncoordinated amine groups in the UiO-66- $\mathrm{NH}_{2}$ are crucial for avoiding the aggregation of $\mathrm{W}$ species. Oppositely, the $\mathrm{W}$ atoms tend to aggregate into nanoclusters or even large nanoparticles without the dangling $-\mathrm{NH}_{2}$ groups. The obtained W SACs exhibited good HER activity under alkaline conditions.

This synthesis approach has been extended for the preparation of other SACs (e.g., Ru SACs) with tailored catalytic reaction properties [152]. Therefore, the recent progress indicates that MOFs have several advantages as templates of SACs. First, different kinds of metal ions are bridged via different organic precursors, ensuring the formation of various functional SACs by pyrolysis MOFs. Second, organic linkers derived heteroatom-doped carbon by pyrolysis can be anchored on SACs [82].

\section{4 $\mathrm{SiO}_{2}$ Template-Assisted Pyrolysis Method}

The use of $\mathrm{SiO}_{2}$ as a template is another method for the synthesis of SACs and was recently reported by Li's group. Briefly, as schematically illustrated in Fig. 4a, a $\mathrm{SiO}_{2}$ 
template is first fabricated and dissolved in a Co-TIPP/ TIPP solution before introducing another precursor. Next, the obtained powder is thermally treated under the $\mathrm{H}_{2} / \mathrm{Ar}$. Finally, the Co SACs can be collected after removing the $\mathrm{SiO}_{2}$ template by $\mathrm{HF}$ (or $\mathrm{NaOH}$ ) solutions. AC-HAADFSTEM along with EELS further demonstrates that the formation of Co SACs and the C, N, Co atoms are uniformly distributed (Fig. 4b-d) [107]. Using a similar approach, Mo, $\mathrm{Cu}, \mathrm{Pt}$, and Pd SACs have been also fabricated by the same group with $\mathrm{SiO}_{2}$, chitosan, and metal salts as precursors. Particularly, the structure of the Mo SACs catalyst was probed by AC-HAADF-STEM and XAFS which indicated the formation of Mo SACs anchored to two carbon atoms and one nitrogen atom $\left(\mathrm{Mo}_{1} \mathrm{~N}_{1} \mathrm{C}_{2}\right)$ [153]. As shown in Fig. 5a-e, the Co SACs with five $\mathrm{Co}-\mathrm{N}$ coordination number embedded in polymer-derived hollow N-C spheres (Co- $\mathrm{N}_{5} / \mathrm{HNPCSs}$ ) have been also prepared by this method [148]. However, the $\mathrm{SiO}_{2}$ template-assisted pyrolysis method would not be a preferred technique in the industry due to the dangerous nature of $\mathrm{HF}$ as a dissolution reagent.

\subsection{Electrodeposition Approach}

Various metal ions can be reduced through the electrochemical cathodic reduction method. The deposition rate of metal ions on the substrate can be adjusted via a change in ion concentration, and then a slow metal ion diffusion rate enables the deposition of SACs on support materials. It is confirmed that $\mathrm{Pt}$ atoms can be dissolved from Pt anodes under both alkaline and acid solutions at high voltages and then redeposited onto cathodes [154]. Based on this phenomenon, Pt foil was utilized as a metal source for depositing Pt SACs supported on CoP nanotube arrays by Luo's group. The obtained Pt SACs supported on CoP nanotube arrays can be directly served as HER electrocatalyst, which exhibited activities comparable to commercial $\mathrm{Pt} / \mathrm{C}$ in neutral solutions ( $\mathrm{pH}=7.2$ ) [53]. Similarly, Pt SACs on the single-wall CNTs can be also obtained by a simple electroplating deposition method [93]. In addition, Xue et al. [155] found that $\mathrm{Ni}$ and Fe SACs can be obtained by an electrodeposition method. In their work, they declared that Ni SACs (1.23 (a)

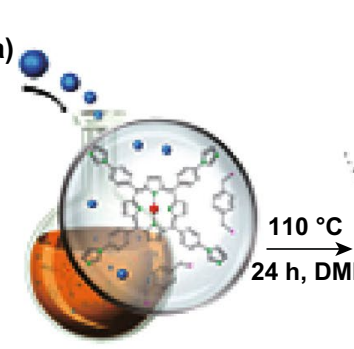

(b)

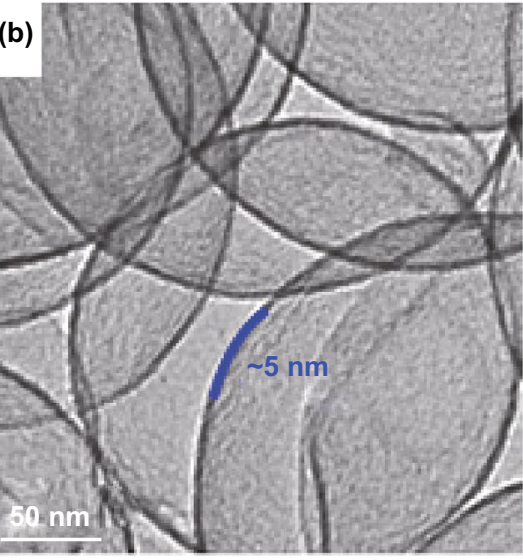

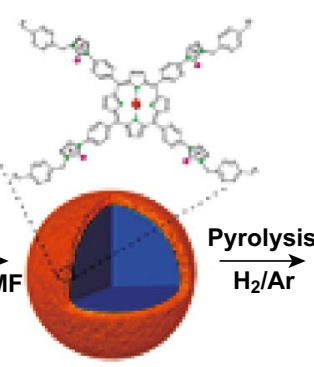

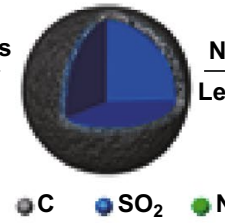

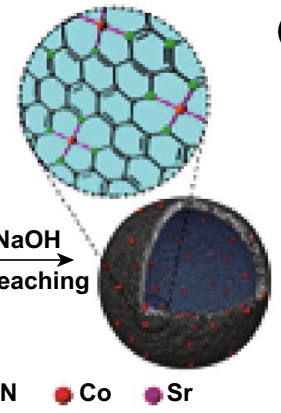

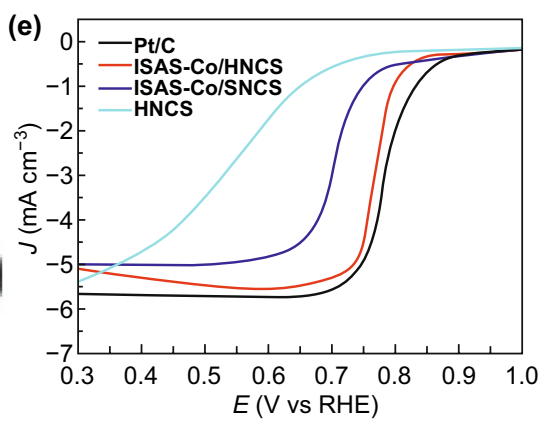

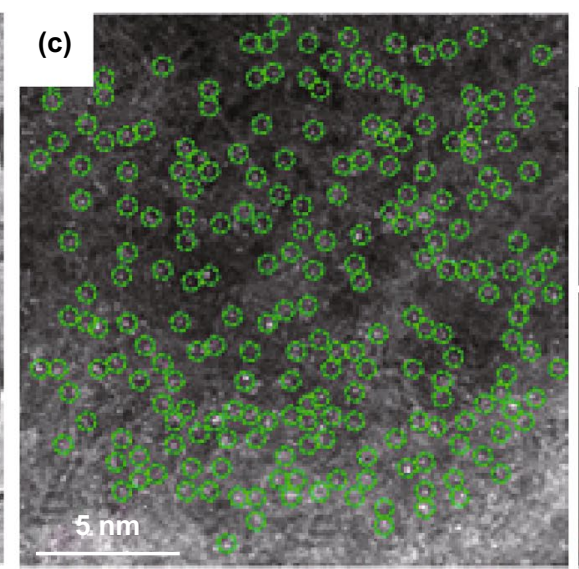
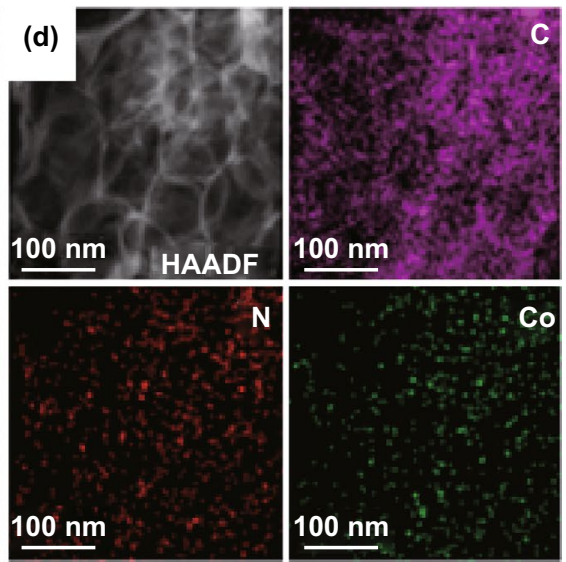

Fig. 4 a The synthetic process of ISAS-Co/HNCS. b TEM and $\mathbf{c}$ AC-HAADF-STEM images of ISAS-Co/HNCS. d HAADF-STEM image and corresponding EDX element mapping of ISAS-Co/HNCS. e ORR polarization curves. a-e Reproduced from Ref. [107] with permission. Copyright 2017 American Chemical Society 
$\AA$ ) and Fe SACs $(1.02 \AA)$ were obtained and these SACs exhibited high HER performance with close to $0 \mathrm{mV}$ onset overpotential, low Tafel slopes, and large turnover frequencies. As illustrated in the experiments, the electrodeposition method for SACs has several advantages: First, the particle size can be well adjusted by changing the deposition parameters such as plating time. Second, the SACs are usually deposited onto the outside surface of the substrate, which is beneficial for the exposure of the active sites. Third, the electrochemical deposition method is fast, scalable, controllable, and efficient [34, 82]. However, there are also disadvantages for this electrodeposition process, such as non-uniform plating (electroplating that results in a substandard appearance of the plated material).

\subsection{High-Temperature Atom Trapping from Bulk Particles}

In the high-temperature atom trapping process, a thermal transport from bulk nanoparticles to the SACs is realized by a simple model system. This approach not only requires the mobile metal species, but also demands a support material that can capture the mobile metal species. As illustrated in Fig. 6a, under high temperatures and oxidizing conditions, $\mathrm{Pt}$ atoms can be emitted to $\mathrm{PtO}_{2}$ molecules [156]. When $\mathrm{PtO}_{2}$ molecules bind to the surfaces of another material that stabilizes the metal-containing precursors, then uniformly dispersed metal SACs can be obtained. Indeed, Datye's group described the preparation of Pt SACs supported on $\mathrm{CeO}_{2}$ by thermal diffusion of Pt nanoparticles [156]. Recently, Li's group reported that precious metal $(\mathrm{Au}, \mathrm{Pd}$, and $\mathrm{Pt}$ ) nanoparticles can be converted to thermally stable noble metal single atoms ( $\mathrm{Au}, \mathrm{Pd}$, and Pt SACs) by utilizing ZIF-8 derived N-C as the anchoring substrate to capture the migrating noble metal atoms at $900{ }^{\circ} \mathrm{C}$ (Fig. 6b) [157]. Interestingly, this phenomenon is existed in non-precious metal system as well. For example, Ni nanoparticles supported on the defective $\mathrm{N}-\mathrm{C}$ can be converted to surface enriched Ni SACs. The authors declared that the Ni nanoparticles play a part of "Pac-Man" to bite off surface C-C bonds. Meanwhile, when Ni nanoparticles diffuse on the $\mathrm{N}-\mathrm{C}$ matrix, the metal (a)

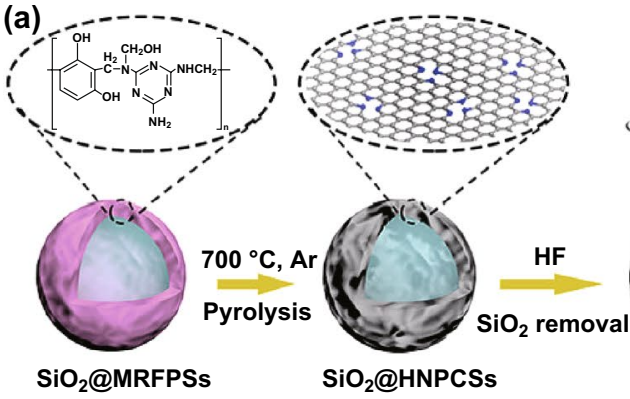

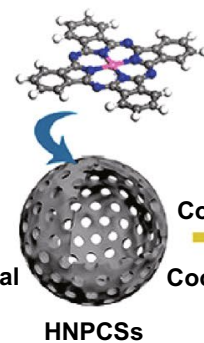

HNPCSs

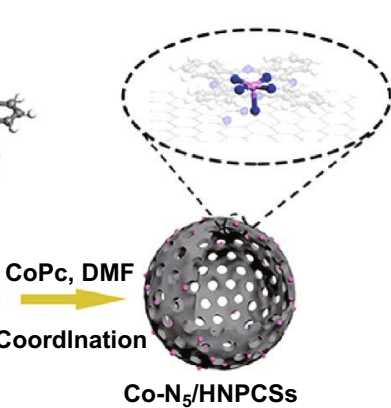

Co-N $\mathrm{N}_{5}$ /HNPCSs
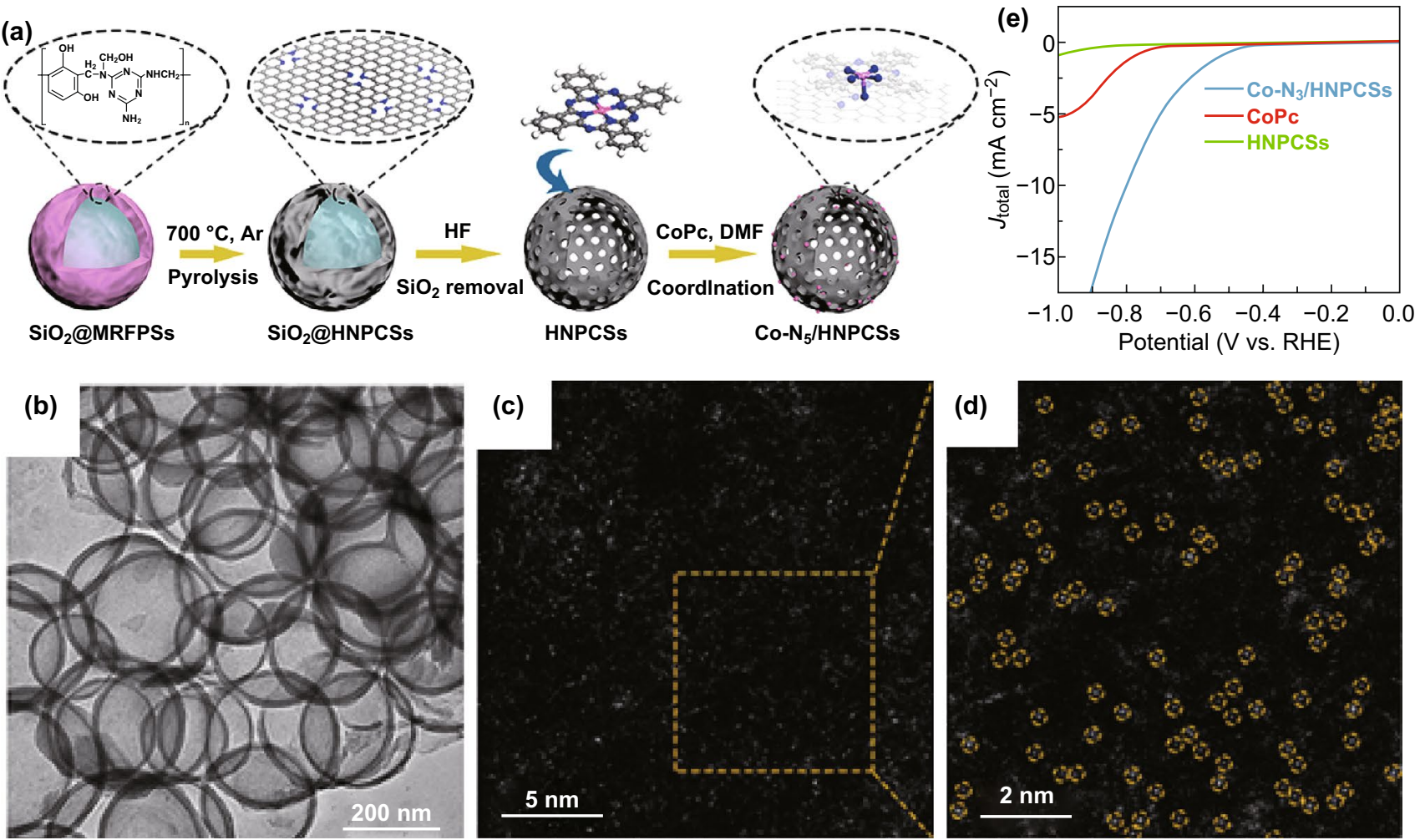

Fig. 5 a Schematic illustration, b TEM, c HAADF-STEM image of Co- $\mathrm{N}_{5} / \mathrm{HNPCS}$. d AC-HAADF-STEM and magnified images of Co-N ${ }_{5} /$ HNPCSs. e LSV curves. a-e Reproduced from Ref. [149] with permission. Copyright 2018 American Chemical Society 
$\mathrm{Ni}$ atoms bound to the N-rich defect sites (Fig. 6c). Therefore, Ni nanoparticles are slowly worn and finally converted to Ni SACs [158].

Furthermore, in order to find a feasible strategy for producing functional SACs at industrial levels, Qu et al. described a facile gas-migration method to directly convert bulk metal materials to SACs. The schematic is shown in Fig. 6d. First, ZIF-8 and commercial $\mathrm{Cu}$ foam are placed separately in a porcelain boat. Second, ZIF-8 is subjected to a pyrolysis process at $900{ }^{\circ} \mathrm{C}$ under Ar atmosphere, forming pyrolyzed ZIF-8 with empty Zn nodes and a large number of defect sites. Subsequently, under $\mathrm{NH}_{3}$ atmosphere, $\mathrm{NH}_{3}$ molecules haul the metal $\mathrm{Cu}$ atoms from the surface of $\mathrm{Cu}$ foam to form volatile $\mathrm{Cu}\left(\mathrm{NH}_{3}\right)_{x}$ species. If such $\mathrm{Cu}\left(\mathrm{NH}_{3}\right)_{x}$ species bind to the defects-rich $\mathrm{N}-\mathrm{C}$ support, then $\mathrm{Cu}$ SACs can be uniformly dispersed on the surface of the N-C support [159]. These high-temperature atom trapping methods provide valuable guidance for the direct preparation of
SACs from non-precious bulk metals $(\mathrm{Cu}, \mathrm{Ni}$, and $\mathrm{Co})$ and show great potential for scaling up SACs toward industrial applications. Additionally, using bulk noble metal (Pt net, Au plate, and Pd plate) as a precursor, Pt SACs, Au SACs, and Pd SACs can be also trapped by the defective graphene (DG). Along with them, the as-obtained Pt SACs/DG shows high activity for the HER [160].

\subsection{Vacancies/Defects Immobilized Strategy}

SACs trapped by defect sites in various substrates (2D materials and transition metal compounds) form a unique class of single-atom catalysts. For example, Wang's group reported the electrochemical exfoliation $\mathrm{Mo}_{2} \mathrm{TiAlC}_{2}$ MXene with $\mathrm{Pt}$ plate as the counter electrode, in which the Mo vacancies can use as the anchoring sites for Pt SACs $\left(\mathrm{Mo}_{2} \mathrm{TiC}_{2} \mathrm{~T}_{x}-\mathrm{PtSA}\right)$. During the electrochemical exfoliation process, single $\mathrm{Pt}$
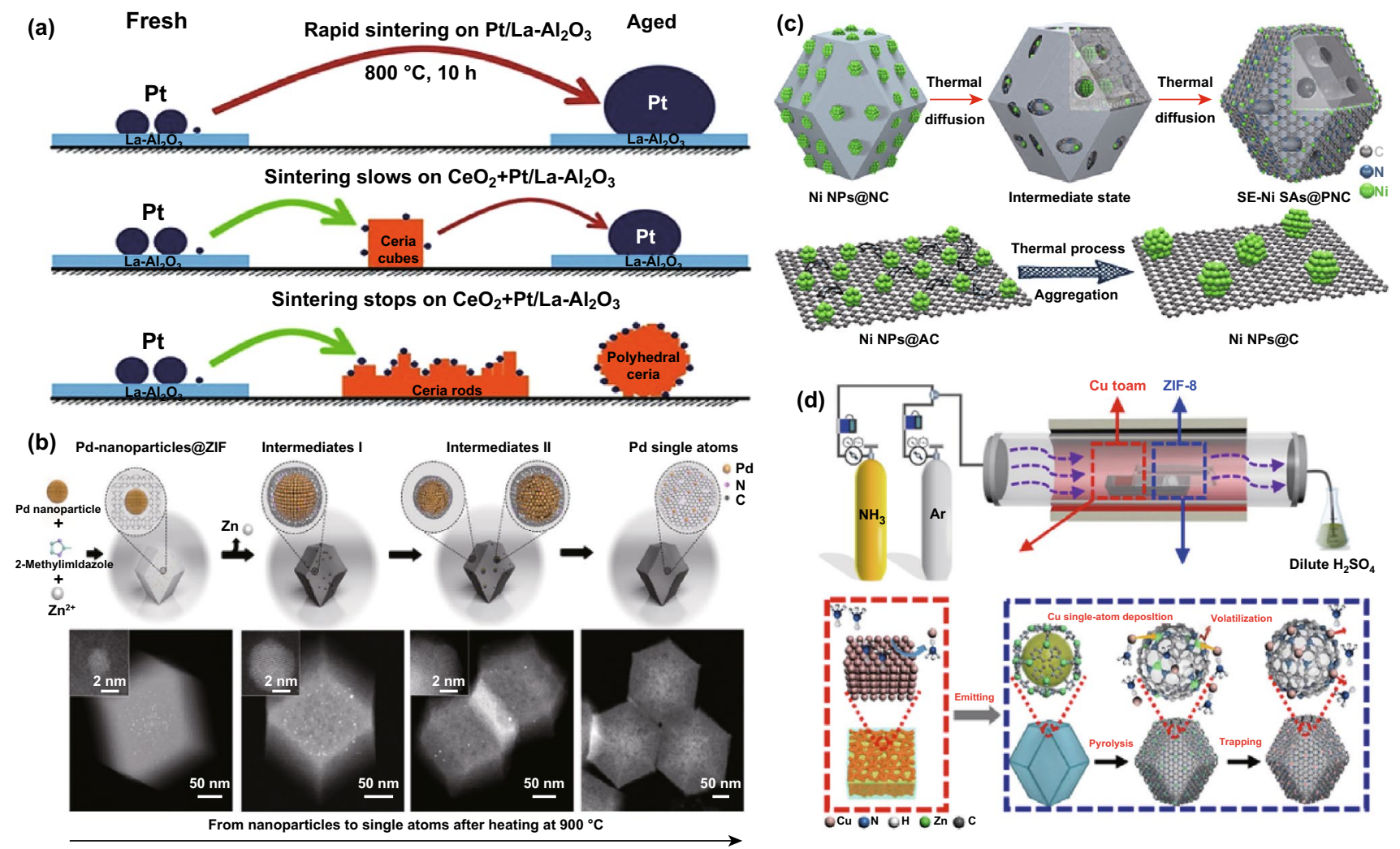

Fig. 6 a Schematic illustration of Pt nanoparticle to Pt SACs. b Schematic illustration of Pd nanoparticle to Pd SACs and structural characterizations of Pd SACs. c Scheme of Ni NPs to Ni SACs transformation and structural characterizations. d Schematic of the synthesis of Cu SACs/N-C. a Reproduced from Ref. [156] with permission. Copyright 2016 American Association for the Advancement of Science. c Reproduced from Ref. [158] with permission. Copyright 2018 Wiley-VCH. b, d Reproduced from Refs. [157, 159] with permission. Copyright 2018 Nature Publishing Group 
atoms are simultaneously immobilized on the Mo vacancies and stabilized via the formation of covalent $\mathrm{Pt}-\mathrm{C}$ bonds with the surrounding $\mathrm{C}$ atoms on the MXene. The resultant $\mathrm{Mo}_{2} \mathrm{TiC}_{2} \mathrm{~T}_{x}$-PtSA materials show Pt-like activity with only $30 \mathrm{mV}$ overpotential at $10 \mathrm{~mA} \mathrm{~cm}^{-2}$ toward HER [161]. Similarly, Chen's group reported a general and facile synthesis approach to fabricate a series of SACs by a simultaneous self-reduction-stabilization process under ambient conditions using 2D Ti-vacancy-rich $\mathrm{Ti}_{3-x} \mathrm{C}_{2} \mathrm{~T}_{\mathrm{y}}$ MXene nanosheets as support. The series of precious and non-precious metal $(\mathrm{M})$ single atoms $(\mathrm{M}=\mathrm{Pt}, \mathrm{Ru}, \mathrm{Rh}, \mathrm{Ir}, \mathrm{Pd}, \mathrm{Fe}$, $\mathrm{Co}$, and $\mathrm{Ni}$ ) can be fabricated through the formation of $\mathrm{M}-\mathrm{C}$ bonds [162]. Besides the defect-rich 2D MXene used as substrates to immobilize the SACs, other vacancies/defects-rich materials also have been used to stabilize SACs, such as vacancy-rich nickel hydroxide [163], oxygen vacancies-rich $\mathrm{MoO}_{2}$ [164], oxygen vacancies on ceria [165].

\subsection{Others Synthetic Approach}

In addition to the above-mentioned synthetic strategy for SACs, many other methods have also been reported by different research groups, including hydrothermal method, iced photochemical reduction, photochemical reduction, and chemical reduction. In particular, Bao's group demonstrated that Pt SACs supported on $\mathrm{MoS}_{2}$ can be obtained by a hydrothermal reduction method. Such materials exhibit an improved HER performance compared to the original $\mathrm{MoS}_{2}$. By combining DFT calculations, they declared that the improved HER performance comes from the tuned hydrogen adsorption free energy [92]. Wei et al. also reported a facile method to fabricate $\mathrm{Pt}$ SACs by photochemical reduction of frozen $\mathrm{H}_{2} \mathrm{PtCl}_{6}$ solution under ultraviolet light irradiation (Fig. 7a). The aggregation of $\mathrm{Pt}$ atoms can be avoided through iced photochemical reduction, and therefore, $\mathrm{Pt}$
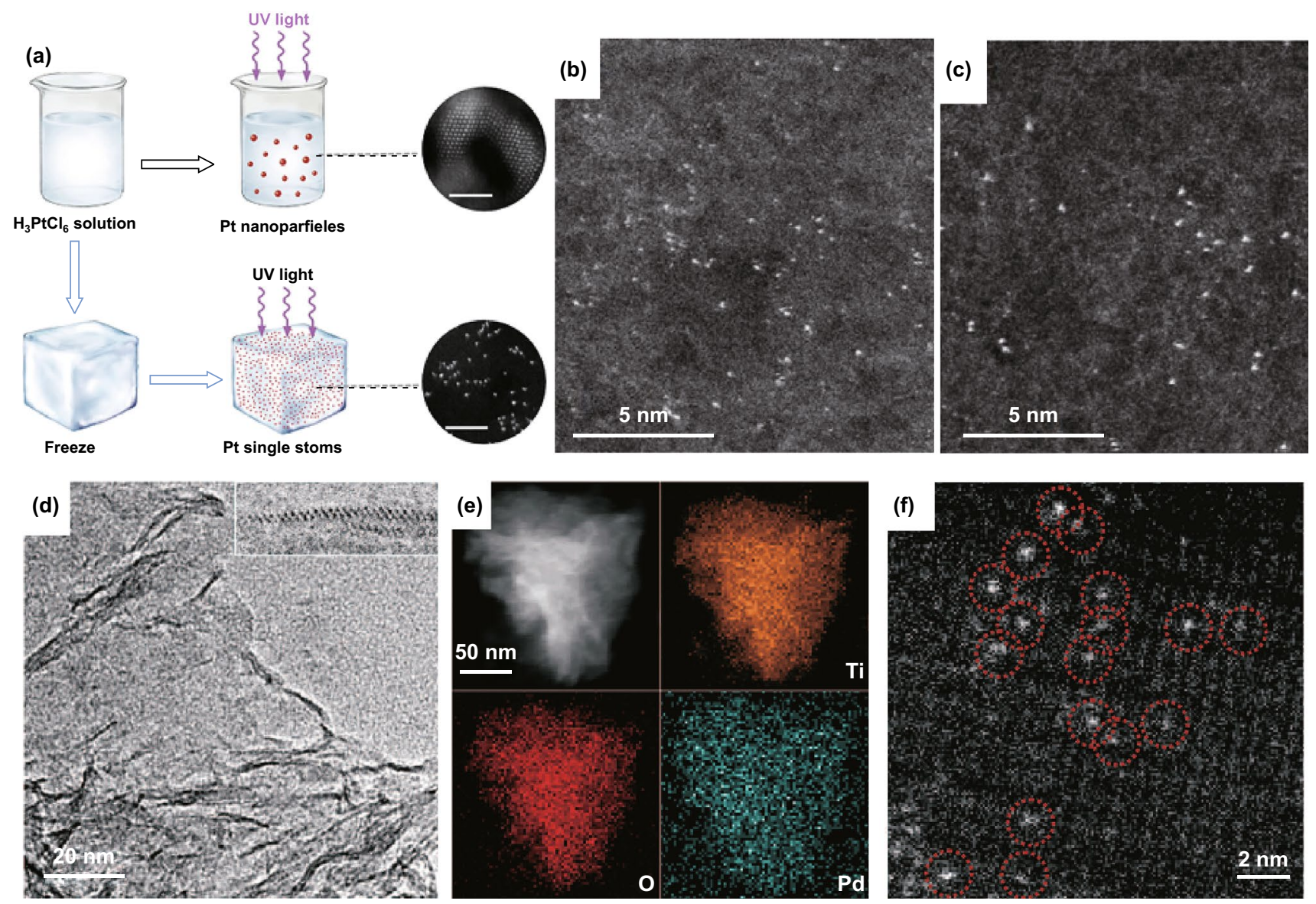

Fig. 7 a Schematic illustration of the iced photochemical process. AC-HAADF-STEM images of b Ag SACs and c Au SACs. d-f Structural characterizations of $\mathrm{Pd}_{1} / \mathrm{TiO}_{2}$. a-c Reproduced from Ref. [125] with permission. Copyright 2015, Royal Society of Chemistry. d-f Reproduced from Ref. [84] with permission. Copyright 2016 Science 
SACs are obtained successfully. Furthermore, the Pt SACs can be deposited on various kinds of substrates (such as $\mathrm{ZnO}$ nanowires, $\mathrm{TiO}_{2}$ nanoparticles, and carbon materials) [125]. Particularly, the Pt SACs on mesoporous carbon showed excellent HER performance with an overpotential of $65 \mathrm{mV}$ at $100 \mathrm{~mA} \mathrm{~cm}^{-2}$ and long-time durability against commercial Pt/C. More importantly, the iced photochemical reduction method can be applied to synthesis Au (Fig. 7b) and Ag SACs (Fig. 7c). In addition, Zheng's group prepared Pd SACs on ultrathin titanium oxide nanosheets with a high Pd loading (1.5 wt \%) by a room-temperature photochemical reduction method (Fig. 7d-f) [84].

\section{Characterization Technology}

In order to confirm the structures and compositions of SACs, a variety of atomic resolution characterization and analytical techniques have been employed, including AC-HAADFSTEM, XAFS spectroscopy [X-ray absorption near-edge structure (XANES) and extended X-ray absorption fine structure (EXAFS)], infrared (IR) spectroscopy, and nuclear magnetic resonance (NMR). In addition, DFT computations have brought unprecedented to discovering catalytic reaction mechanism and predicting the catalytically active species.

\subsection{Electron Microscopy Techniques}

Figure 8a shows an optical photograph of the preparing process of the nitrogen-doped graphene-supported atomic cobalt (denoted as Co-NG) catalyst. First, the GO and Co salt are dissolved in deionized water. Then the dried sample is obtained by lyophilization. Finally, the Co-NG sample is formed via annealing the dried precursor under the $\mathrm{NH}_{3}$ atmosphere. The scanning electron microscopy (SEM) image of Co-NG displays that $\mathrm{Co}-\mathrm{NG}$ has similar morphological features as graphene (Fig. 8b). Figure $8 \mathrm{c}$ further shows Co-NG nanosheets with ripple surface features. In addition, no cobalt nanoparticles can be found on the Co-NG materials. It is worth noting that the Co-NG material can be formed into a paper-like form (Fig. 8d). AC-HAADF-STEM imaging technique was applied to characterization the Co SACs. As shown in Fig. 8e-g, the AC-HAADF-STEM images clearly confirm that Co SACs dispersed on the defects-rich carbon matrix.

\subsection{X-Ray Spectroscopy}

XANES and EXAFS technologies are widely used for the characterization of the chemical state and the coordination structure of SACs [121]. For example, as presented in Fig. 9a, the Fe K-edge of XANES for $\mathrm{FeN}_{4} / \mathrm{GN}$ samples shows a near-edge structure different from those of $\mathrm{Fe}_{2} \mathrm{O}_{3}$ and $\mathrm{Fe}$ foil but similar to that of the iron precursor ( $\mathrm{FePc}$ ), confirming that the valence state of $\mathrm{Fe}$ for $\mathrm{FeN}_{4} / \mathrm{GN}$ samples remains the same as that of FePc. The Fourier transform (FT) spectra (Fig. 9b) for $\mathrm{FeN}_{4} / \mathrm{GN}$ samples clearly show that the $\mathrm{Fe}$ atoms are atomically dispersed; $\mathrm{Fe}-\mathrm{Fe}$ bonds are absent [166]. In addition, the atomic Co dopants on the support were also investigated by Pan et al. using XAFS measurements. As shown in Fig. 9c, the Co-K-edge of XANES for $\mathrm{Co}-\mathrm{N}_{5} / \mathrm{HNPCSs}$ shows a similar near-edge structure to that of CoPc. Furthermore, the FT $\mathrm{k}^{3}$-weighted EXAFS spectra (Fig. 9e) exhibit Co-N bonds with a peak at $1.5 \AA$, and Co-Co paths at $2.2 \AA$ were not found. When further fitting EXAFS to the quantitative coordination configuration of Co atoms, the Co-N coordination number is five. All of these results demonstrated that the atomic dispersion of $\mathrm{Co}$ atoms is formed in $\mathrm{Co}-\mathrm{N}_{5} / \mathrm{HNPCSs}$ material. It is worth noting that the $\mathrm{Co}$ atomic structure model is illustrated in Fig. 9f (the Co-N coordination number is five) [149].

\subsection{Other Complementary Technologies}

In addition to AC-HAADF-STEM and XAFS spectroscopy, magic-angle spinning (MAS) NMR and IR are also useful characterization techniques toward SACs. Particularly, solid-state MAS NMR technique is employed to study the anchoring of monoatomic Pt at very low loadings [167]. The coordination-unsaturated penta-coordinated $\mathrm{Al}^{3+}$ was confirmed as the anchoring point of Pt SACs on the surface of the $\gamma-\mathrm{Al}_{2} \mathrm{O}_{3}$ support. Corma et al. [168] also exhibit the presence of Au SACs by the NMR technique. IR spectroscopy can directly detect the interaction between the adsorbed molecule and the surface of the support. The characteristics of the active center can be inferred by appropriate correction by detecting the vibration frequency and intensity of the model. And then the condition of the overall catalyst can be analyzed, which is an important means for characterizing SACs [169, 170]. 

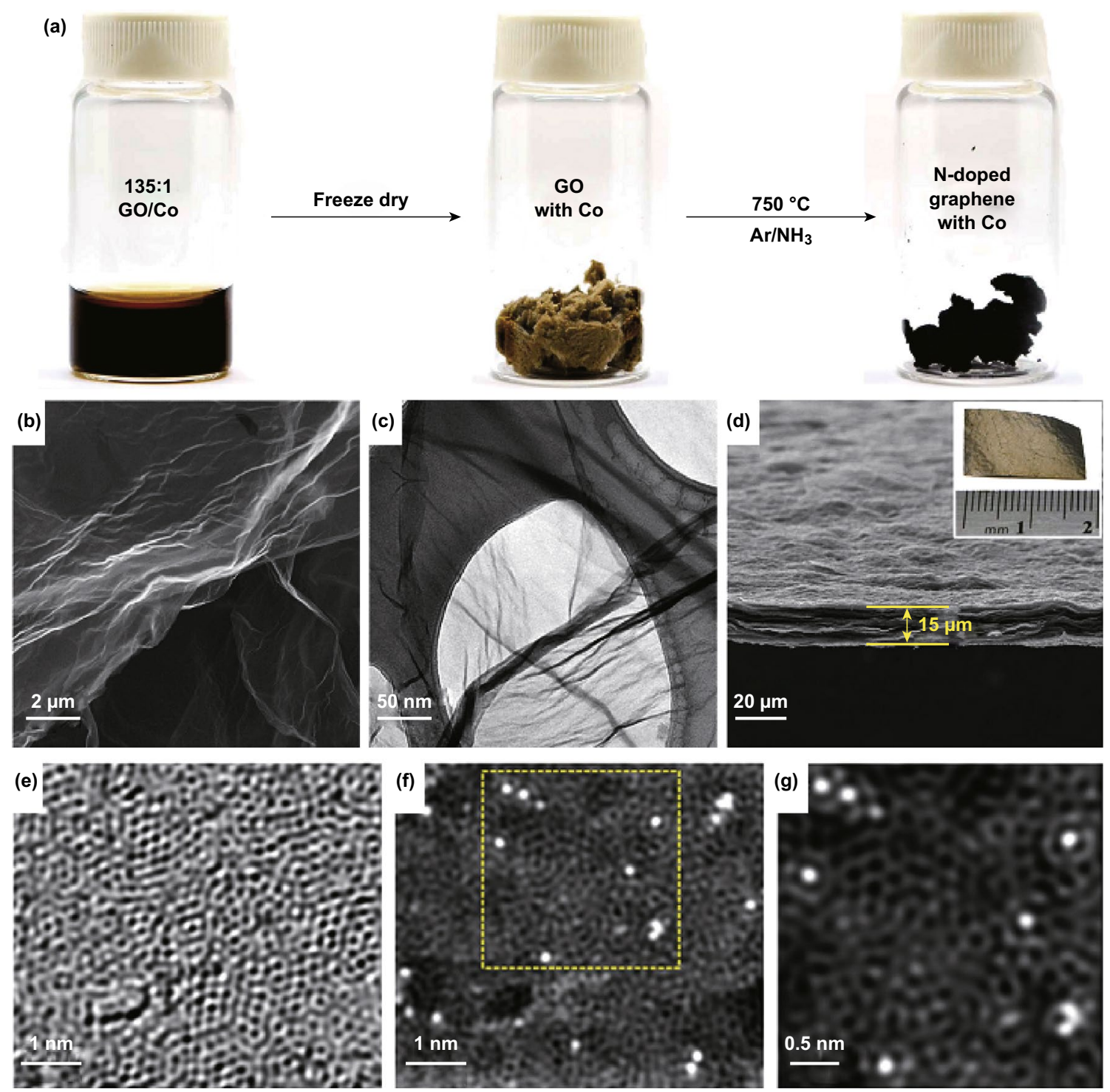

Fig. 8 a The synthetic procedure of the Co-NG material. b SEM, c TEM and d cross-sectional SEM image of Co-NG nanosheets. e Brightfield aberration-corrected STEM image of the Co-NG. $\mathbf{f}$ HAADF-STEM image of the Co-NG. $\mathbf{g}$ The enlarged view of the selected area in $\mathbf{f}$. Panels are reproduced from Ref. [94] with permission. Copyright 2015 Nature Publishing Group

\subsection{DFT Computations}

Besides the basic structure characterization, on the one hand, a theoretical study based on DFT has brought unprecedented to predicted catalytic activity through build the structure model, allowing the rational design of materials with tailored performance. For example, by using DFT, Zhou et al. investigated a number of SACs $(\mathrm{Ni}, \mathrm{Cu}, \mathrm{Fe}, \mathrm{Co}$, and $\mathrm{Pd})$ embedded in nitrogen-doped graphenes as both OER and
HER catalysts. They concluded that a high-coordinated Co center, e.g., a quadruple-coordinated $\mathrm{Co}$, shows a good OER performance, whereas a low-coordinated Co site, e.g., a triple-coordinated Co, is a good candidate for HER [171]. Likewise, Wang's group presented a bifunctional singleatom catalyst by DFT simulation. To this end, $\beta_{12}$-boron monolayer $\left(\beta_{12}\right.$-BM)-supported Ni SACs exhibited the best full water splitting performance into the $\mathrm{TM}_{1} / \beta_{12}$-BM $(\mathrm{TM}=\mathrm{Fe}, \mathrm{Ti}, \mathrm{Co}, \mathrm{V}, \mathrm{Ni}$, and Mn) SACs systems [172]. 

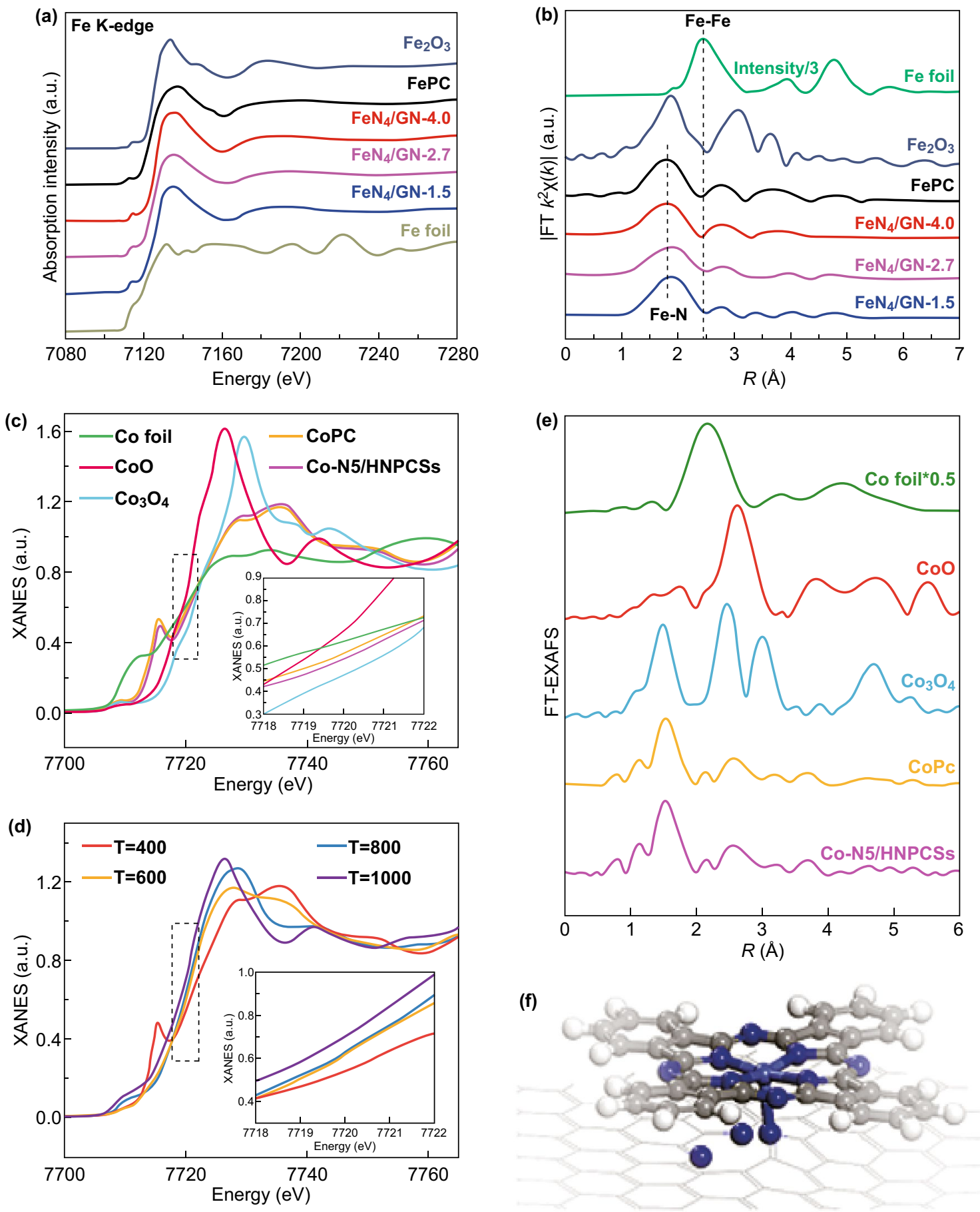

Fig. 9 a Fe K-edge XANES and b FT-EXAFS signals for $\mathrm{FeN}_{4} / \mathrm{GN}, \mathrm{FePc}, \mathrm{Fe}$ foil, and $\mathrm{Fe}_{2} \mathrm{O}_{3}$. XANES spectra at the $\mathrm{Co} \mathrm{K}^{-e d g e}$ of $\mathbf{c} \mathrm{Co}_{3} \mathrm{O}_{4}$, $\mathrm{Co}$ foil, $\mathrm{CoO}$, and $\mathrm{Co}-\mathrm{N}_{5} / \mathrm{HNPCSs}, \mathbf{d}$ Co- $\mathrm{N}_{5} / \mathrm{HNPCSs}-\mathrm{T}$ (inset is the magnified image), e FT at R space, $\mathbf{f}$ schematic model, $\mathrm{C}$ (gray), $\mathrm{N}$ (blue), Co (wathet), and H (white). a-b Reproduced from Ref. [78] with permission. Copyright 2017 Wiley-VCH. c-f Reproduced from Ref. [149] with permission. Copyright 2018 American Chemical Society. (Color figure online) 
In addition, Ling et al. demonstrated that $\mathrm{Mo}_{1}-\mathrm{N}_{1} \mathrm{C}_{2}$ possesses ultra-high NRR catalytic activity in a series of SACs of $\mathrm{M}_{1}-\mathrm{N}_{1} \mathrm{C}_{2}(\mathrm{M}=\mathrm{Cu}, \mathrm{Mo}, \mathrm{Pd}$, and $\mathrm{Pt})$ basis of first-principles computations [120]. On the other hand, understanding the catalytic reaction mechanism is crucial to the rational design of high activity catalysts. Therefore, DFT calculations also have been used to investigate the catalytic reaction mechanism. For example, the hydrogen adsorption free energy $\left(\Delta G_{\mathrm{H}^{*}}\right)$ is an important descriptor of HER activity. Therefore, the values of $\Delta G_{\mathrm{H}^{*}}$ can be used to compare the HER catalytic activity of different catalysts and generally the closer to zero, the better [147]. Furthermore, researchers can easily understand the local atomic structure and coordination atom information by constructed the DFT model.

\section{Applications of SACs in Electrochemical HER}

As reported, SACs are attractive catalysts that can provide a unique opportunity to tune the catalytic reaction activity and selectivity. For example, Ru SACs have been used as efficient catalysts for HER, ORR, NRR, alcohols oxidation reaction (AOR), and $\mathrm{CO}_{2}$ hydrogenation (Figs. 10, 11) [106, 126, 151, 173, 174]. Hydrogen, as a new ideal energy source, is significant to develop fuel cells. Herein, we highlight the recent development of SACs for electrochemical HER applications. HER is a half-reaction that takes place at the cathode during the water splitting. In fact, the HER reaction mechanism is different under acidic and alkaline conditions as represented in Eqs. 1-6:

Acidic media:

Volmer reaction: $\mathrm{H}^{+}+\mathrm{e}^{-} \rightarrow \mathrm{H}^{*}$

Heyrovsky reaction: $\mathrm{H}^{*}+\mathrm{H}^{+}+\mathrm{e}^{-} \rightarrow \mathrm{H}_{2}$

Tafel reaction: $\mathrm{H}^{*}+\mathrm{H}^{*} \rightarrow \mathrm{H}_{2}$

Alkaline media:

Volmer reaction: $\mathrm{H}_{2} \mathrm{O}+\mathrm{e}^{-} \rightarrow \mathrm{H}^{*}+\mathrm{OH}^{-}$

Heyrovsky reaction: $\mathrm{H}^{*}+\mathrm{H}_{2} \mathrm{O}+\mathrm{e}^{-} \rightarrow \mathrm{H}_{2}+\mathrm{OH}^{-}$

Tafel reaction: $2 \mathrm{H}_{2} \mathrm{O}+2 \mathrm{e}^{-} \rightarrow \mathrm{H}_{2}+2 \mathrm{OH}^{-}$

\subsection{Pt Group SACs}

Generally, Pt group-based materials are the most active electrocatalysts for HER with large current densities, low overpotential, and good stability. However, they suffer from high cost and scarcity, which limit their extensive application. To solve these problems, many researchers have been carried out to develop low-loading of noble metal HER electrocatalysts. Interestingly, SACs are ideal methods to resolve such problems and are expected to display excellent activity toward HER. For example, Lou's group reported Pt SACs in a nitrogen-containing porous carbon matrix (Pt@ PCM) which can be obtained by a high-temperature atom trapping method (Fig. 12a, b). After HER tests, the Pt@ PCM catalyst exhibits 25 times mass activity than that of commercial $20 \mathrm{wt} \% \mathrm{Pt} / \mathrm{C}$ catalyst (Fig. 12c, d). Results of EXAFS investigation and DFT calculations suggested that the active centers are the lattice-confined Pt sites [175]. In addition, Pt SACs dispersed on graphdiyne (GDY) have also been synthesized by the coordination interactions between $\mathrm{Pt}$ atoms and alkynyl $\mathrm{C}$ atoms in GDY, with the formation of four-coordinated $\mathrm{C}_{2}-\mathrm{Pt}_{-} \mathrm{Cl}_{2}$ species (Pt-GDY2). Importantly, Pt-GDY2 shows excellent HER catalytic activity, with an enhanced mass activity in comparison with the $20 \mathrm{wt} \%$ commercial Pt/C catalysts (Fig. 12h) [176]. Cheng et al. [52] obtained Pt SACs and clusters supported on the nitrogendoped graphene nanosheet substrate by the ALD method, which also exhibited high HER activity. Due to the low price of Ru which is $4 \%$ cheaper than Pt [106], Ru SACs supported on amorphous phosphorus nitride imide nanotubes (HPN) have also been synthesized by Wu and coworkers. The obtained Ru SACs supported on HPN showed excellent catalytic activity and robust durability in acid solutions toward HER [126].

Traditionally, transition metal phosphides (TMPs) and chalcogenides (TMCs) have been widely studied as HER electrocatalyst due to their excellent activity. Therefore, SACs supported on TMPs and TMCs are expected to show outstanding HER performance. Indeed, Luo's group fabricated Pt SACs on CoP nanotube arrays ( $\mathrm{Pt} \mathrm{SACs} / \mathrm{CoP}$ ) through the electrodeposition method. The Pt SACs/CoP (Pt loading: $1.76 \mathrm{wt} \%$ ) shows better HER activity than that of commercial $20 \mathrm{wt} \% \mathrm{Pt} / \mathrm{C}$ [53]. Deng et al. also prepared $\mathrm{Pt}$ SACs (Fig. 13a-c) uniformly dispersed on $\mathrm{MoS}_{2}\left(\mathrm{Pt}-\mathrm{MoS}_{2}\right)$, 


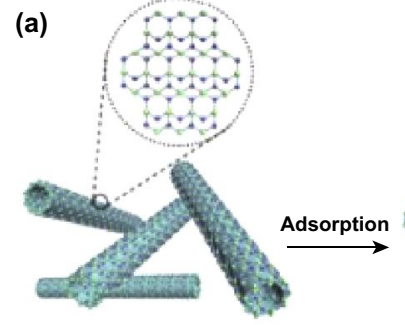

HPN

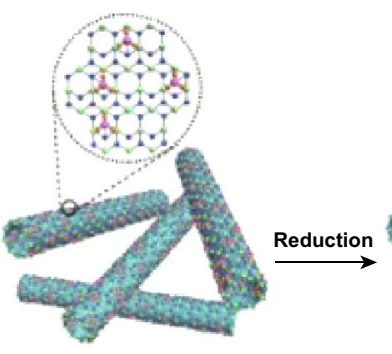

$\mathrm{RuCl}_{3} @ \mathrm{HPN}$
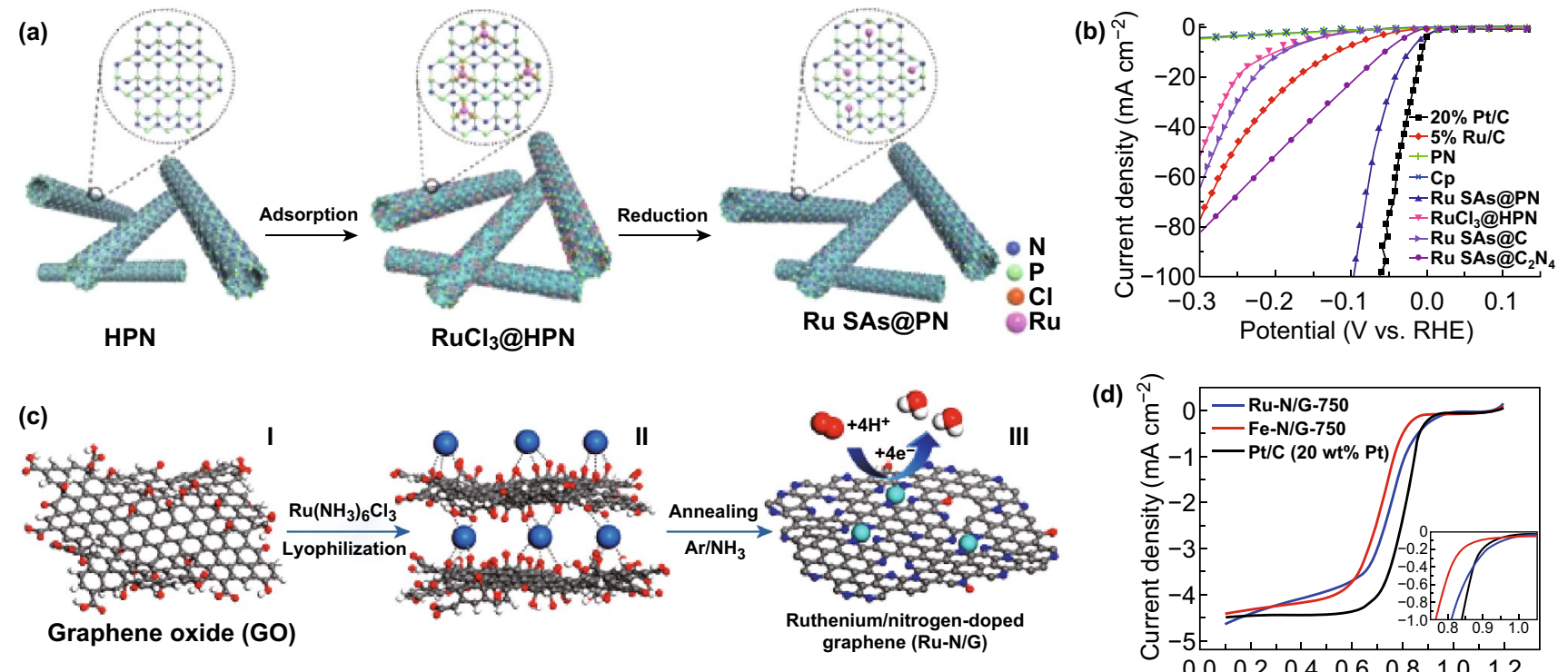

(d)

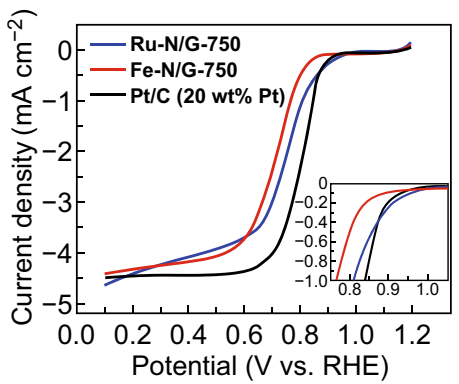

(e)
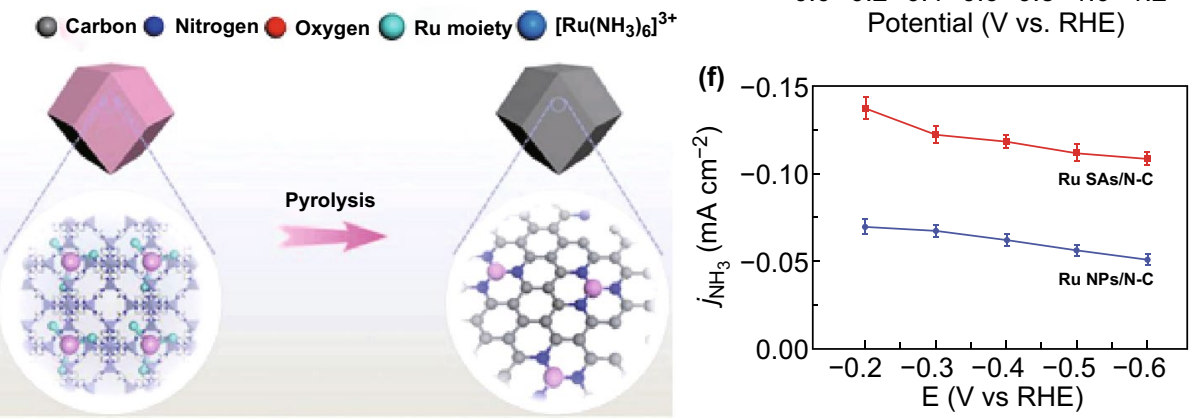

Fig. 10 a Preparation process of Ru SAs@PN. b Polarization curves of the samples. c The synthetic process for the Ru-N/G-750. d Polarization curves of $\mathrm{Ru}-\mathrm{N} / \mathrm{G}-750, \mathrm{Fe}-\mathrm{N} / \mathrm{G}-750$ and $\mathrm{Pt} / \mathrm{C}$ in $\mathrm{O}_{2}$-saturated $0.1 \mathrm{M} \mathrm{HClO}_{4}$ solutions. e Scheme of the synthetic procedure for Ru SAs/N-C. f Current densities for $\mathrm{NH}_{3}$ production. a, b, e, f Reproduced from Refs. [126, 173] with permission. Copyright 2018 Wiley-VCH. c, d Reproduced from Ref. [106] with permission. Copyright 2017 American Chemical Society

showing significantly boosted HER activity compared with original $\mathrm{MoS}_{2}$ (Fig. 13d) [92]. In addition, Xing and coworkers fabricated different loading of single Pd atoms doped $\mathrm{MoS}_{2}$ (Fig. 13e, f). The 1\% Pd-MoS 2 shows the best HER catalytic activity with a low overpotential of $89 \mathrm{mV}$ at a current density of $10 \mathrm{~mA} \mathrm{~cm}^{-2}$ (Fig. 13g) [177]. Guan et al. [178] designed and prepared special ganoderma-like $\mathrm{MoS}_{2} /$ $\mathrm{NiS}_{2}$ heterostructures with dispersed $\mathrm{Pt}$ atoms which showed impressive HER performance. Despite such progress on the Pt group SACs, their large-scale commercialization is still hindered by their scarcity and high cost. Thus, it is worthwhile to develop non-noble metal-based SACs due to their relatively abundant and cheaper resource.

\subsection{Fe-, Co-, Ni-Based SACs}

Tour's group reported a low-cost, simple, and scalable method to preparing Co SACs by simply heat-treating cobalt salts and graphene oxide under $\mathrm{NH}_{3}$ atmosphere for the first time. The Co-NG catalysts exhibit excellent HER activity under both acidic and alkaline conditions (Fig. 14a, b). They also suggested that the catalytically active centers originate from Co metal centers coordinated to the $\mathrm{N}$ atoms [95]. In addition, Fan et al. [179] reported that a Ni-C-based material can be activated to obtain the Ni SACs on graphitic carbon after 4000 cyclic voltammograms cycles, consequently displaying high catalytic 


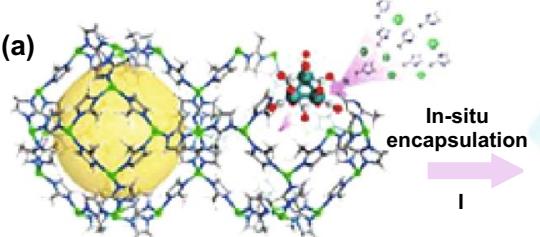

\&. $\mathrm{Ru}_{3}(\mathrm{CO})_{12} \odot \mathrm{Zn}^{2+}, \mathrm{C}$ 2-Methylimidazole

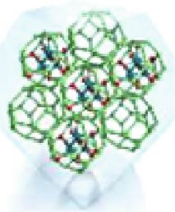

$\mathrm{Ru}_{3}(\mathrm{CO})_{12} @ \mathrm{ZIF}-8$

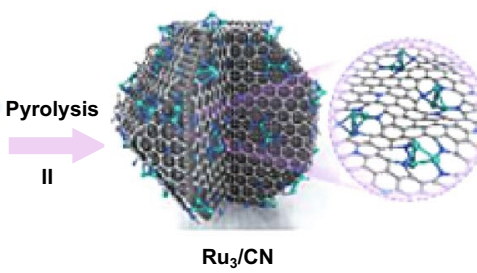

$\mathrm{Ru}_{3} / \mathrm{CN}$

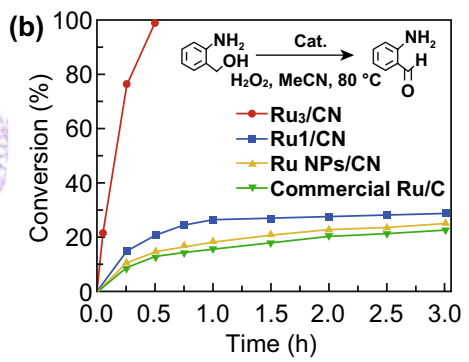

(c)

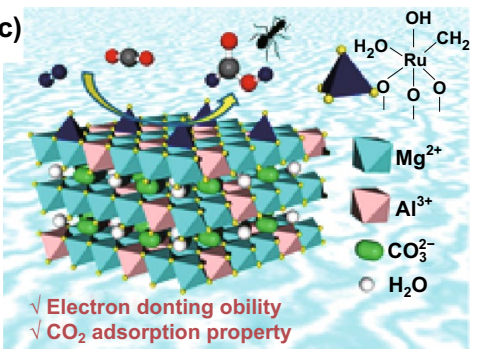

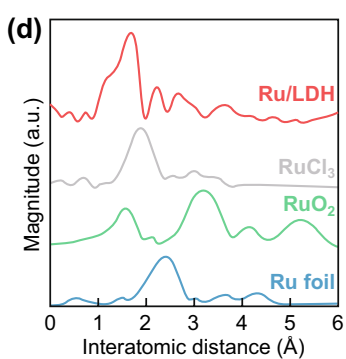

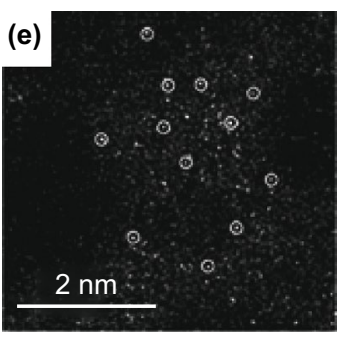

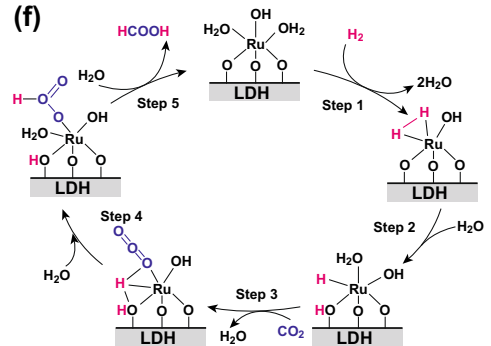

Fig. 11 a Illustration of the preparation process of $\mathrm{Ru}_{3} / \mathrm{CN}$. b Conversion $(\%)$ of 2-aminobenzylalcohol versus time for $\mathrm{Ru}_{3} / \mathrm{CN}, \mathrm{Ru} / \mathrm{CN}, \mathrm{Ru}$ NPs/CN, and commercial Ru/C. c Schematic illustration of the hydrogenation. d Ru K-edge FT-EXAFS spectra. e HAADF-STEM image of $\mathrm{Ru} / \mathrm{LDH}$. f Possible reaction pathway for $\mathrm{CO}_{2}$ hydrogenation to produce formic acid with a Ru/LDH catalyst. Panels are reproduced from Refs. $[151,174]$ with permission. Copyright 2017 American Chemical Society
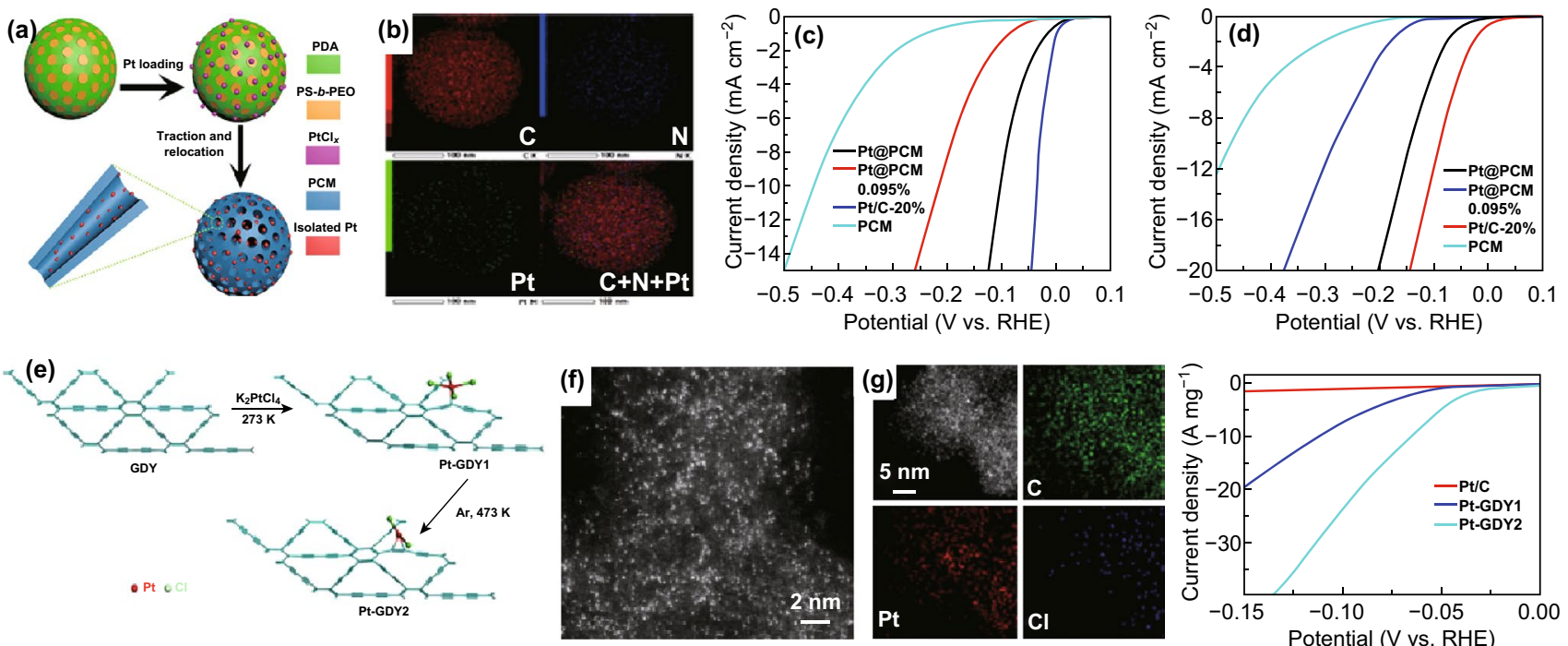

Fig. 12 a The synthetic process of Pt@PCM. b Element mapping images of Pt@PCM. Polarization curves of samples in $\mathbf{c} 0.5 \mathrm{M} \mathrm{H}_{2} \mathrm{SO}_{4}$ and d $1.0 \mathrm{M} \mathrm{KOH}$ solutions. e The formation of Pt-GDY1 and Pt-GDY2. f AC-HAADF-STEM images for PtGDY2. g Elemental mapping for PtGDY2. (h) The polarization curves for Pt-GDY2, Pt-GDY1, and c Pt/C in acidic solution. a-d Reproduced under the terms of the CC-BY 4.0 license. Ref. [175]. Copyright 2018, American Association for the Advancement of Science. e-h Reproduced from Ref. [176] with permission. Copyright 2018 Wiley-VCH

activity and durability for HER (Fig. 14c-f). Similarly, Chen's group developed Ni SACs embedded in nanoporous graphene which also exhibited superior catalytic activities and stability in water splitting reactions under acidic conditions [180]. Fe SACs have also been widely reported by different researchers, because element Fe is one of the most abundant and cheapest transition metals [150, 155, 166, 181]. For example, recently, Xue et al. reported a facile and precise anchoring of the Fe SACs on graphdiyne (Fe/GD) by electrodeposition method using $\mathrm{Fe}^{3+}$ 

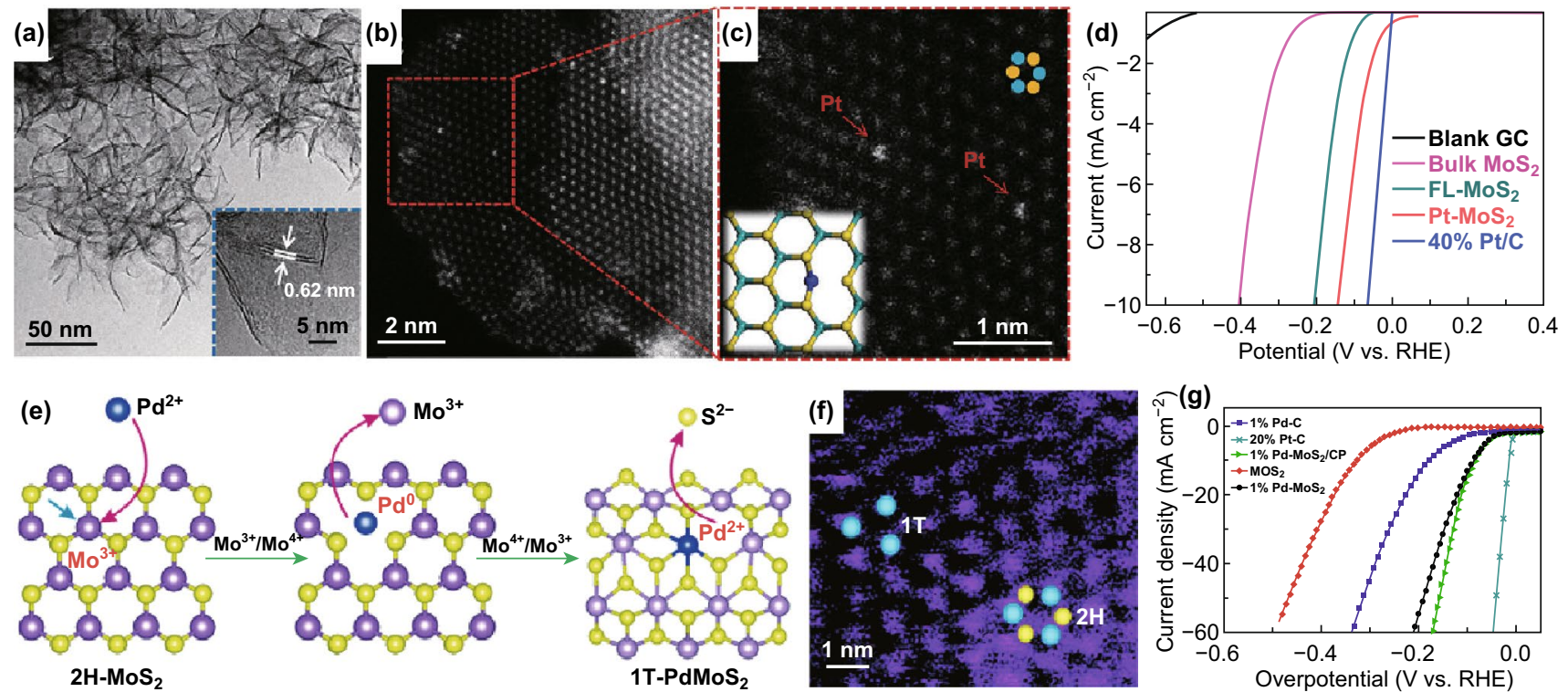

Fig. 13 a TEM and b HAADF-STEM images of Pt-MoS 2 . c Magnified domain with red dashed rectangle in b. d Polarization curves for bulk $\mathrm{MoS}_{2}, \mathrm{FL}-\mathrm{MoS}_{2}, \mathrm{Pt}-\mathrm{MoS}_{2}$, and $40 \% \mathrm{Pt} / \mathrm{C}$. e Schematic illustration of the spontaneous $\mathrm{MoS}_{2} / \mathrm{Pd}$ (II) redox reaction. f Dark-field STEM image of the $1 \% \mathrm{Pd}-\mathrm{MoS}_{2}$. g Polarization curves of $1 \% \mathrm{Pd}-\mathrm{MoS}_{2} / \mathrm{CP}, 1 \% \mathrm{Pd}-\mathrm{MoS}_{2}$, pure $\mathrm{MoS}_{2}, 1 \% \mathrm{Pd}-\mathrm{C}$, and $20 \% \mathrm{Pt} / \mathrm{C}$. a-d Reproduced from Ref. [92] with permission. Copyright 2015 Royal Society of Chemistry. e-g Reproduced from Ref. [177] with permission. Copyright 2018 Nature Publishing Group

and graphdiyne as a precursor (Fig. 15a). Fe/GD exhibits high HER activity with only $66 \mathrm{mV}$ overpotential at $10 \mathrm{~mA} \mathrm{~cm}^{-2}$ (Fig. 15d). Additionally, the atomic-level identification of the active structure during the alkaline HER has been reported recently. They demonstrated that the formation of a high-valence $\mathrm{HO}-\mathrm{Co}_{1}-\mathrm{N}_{2}$ moiety by the binding between isolated $\mathrm{Co}_{1}-\mathrm{N}_{4}$ sites with electrolyte hydroxide further unravels the preferred water adsorption reaction intermediate $\mathrm{H}_{2} \mathrm{O}-\left(\mathrm{HO}-\mathrm{Co}_{1}-\mathrm{N}_{2}\right)$. This result is critical to industrial water-alkali electrolyzers, which remains elusive and is a field of intense research [182].

\subsection{Other Transition Metal-Based SACs}

Traditionally, Mo- and W-based materials are also excellent catalysts for HER. Therefore, it is interesting to investigate the HER activity of Mo and W SACs. Indeed, Wang and coworkers demonstrated that W SACs with high HER performance can be obtained by the MOF-derived method
(Fig. 16a, e). HAADF-STEM and XAFS spectroscopy analyses show the formation of W SACs anchored with three $\mathrm{C}$ atoms and one $\mathrm{N}$ atom $\left(\mathrm{W}_{1} \mathrm{~N}_{1} \mathrm{C}_{3}\right)$ (Fig. 16b-d). DFT calculations further demonstrated that the unique structure of the $\mathrm{W}_{1} \mathrm{~N}_{1} \mathrm{C}_{3}$ moiety plays a critical role in improving HER activity [148]. Additionally, Mo SACs were obtained with the help of chitosan by the same group. Similarly, the structure of Mo SACs was probed by XAFS spectroscopy and AC-HAADF-STEM, suggesting the formation of Mo SACs anchored with two carbon atoms and one nitrogen atom $\left(\mathrm{Mo}_{1} \mathrm{~N}_{1} \mathrm{C}_{2}\right)$ (Fig. 16f-k). The $\mathrm{Mo}_{1} \mathrm{~N}_{1} \mathrm{C}_{2}$ material displays outstanding HER performance compared with bulk MoN and $\mathrm{Mo}_{2} \mathrm{C}$ and better durability than $20 \mathrm{wt} \%$ commercial Pt/C (Fig. 161, m). DFT calculations further reveal that $\mathrm{Mo}_{1} \mathrm{~N}_{1} \mathrm{C}_{2}$ is more beneficial for HER electrocatalysis than $\mathrm{MoN}$ and $\mathrm{Mo}_{2} \mathrm{C}$ (Fig. 16n, o) [154]. Recently, Du's group demonstrated that V SACs supported on graphene is also a highly active HER electrocatalyst through DFT calculations [183]. It was suggested that V SACs embedded in the graphene can substantially tune the free energy of hydrogen adsorption 

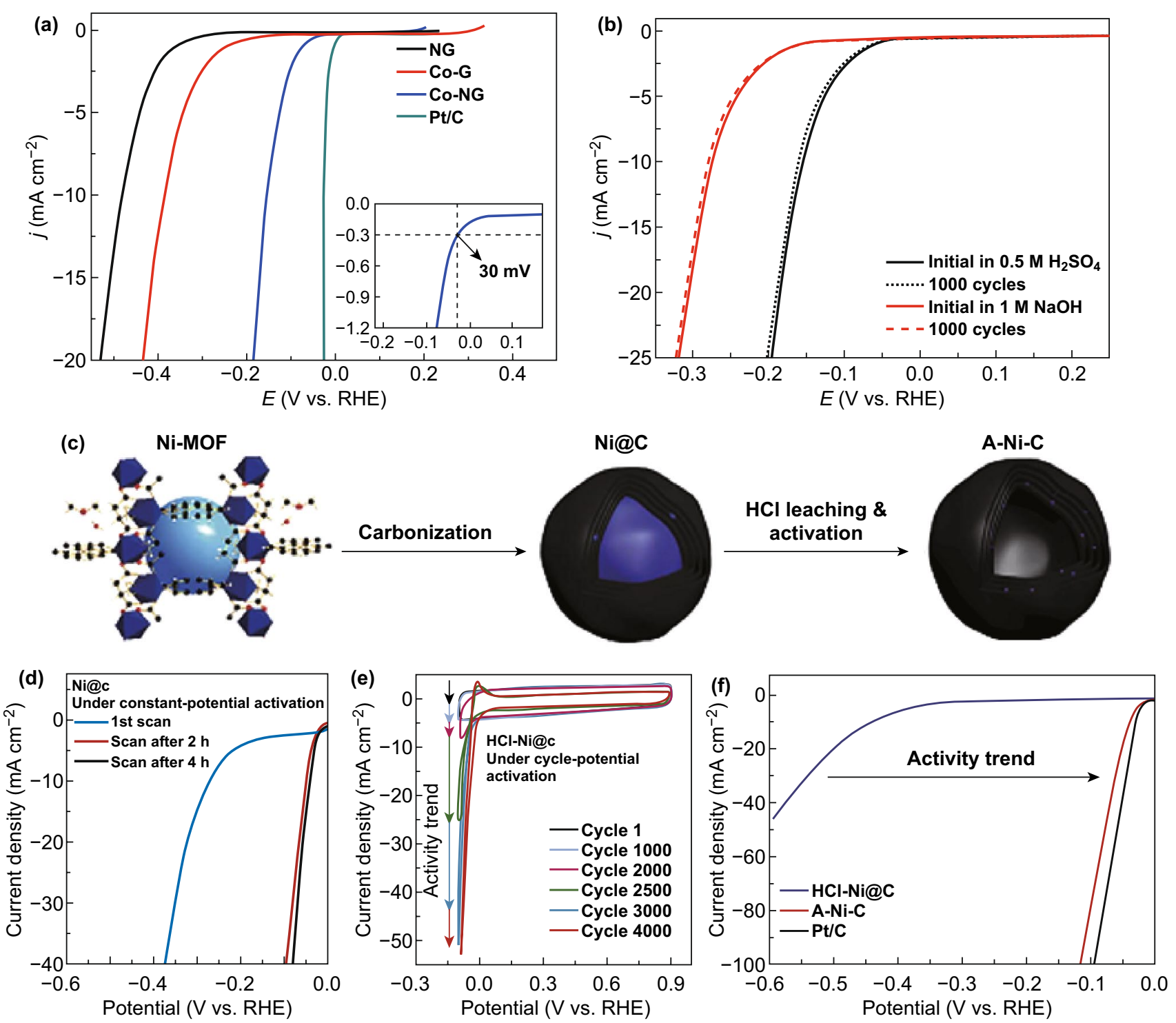

Fig. 14 a The polarization curves of $\mathrm{Co}-\mathrm{G}, \mathrm{NG}, \mathrm{Co}-\mathrm{NG}$ and commercial $\mathrm{Pt} / \mathrm{C}$ in acidic solutions. b Polarization curves for the Co-NG before and after $1000 \mathrm{CV}$ cycles in acidic and alkaline solutions, respectively. $\mathbf{c}$ The preparation and activation process of the Ni-C materials. $\mathbf{d}$ Polarization curves before and after activation at a constant potential. e CVs of $\mathrm{HCl}-\mathrm{Ni} @ \mathrm{C}$. f Polarization curves for A-Ni-C, HCl-Ni@C, and Pt/C catalysts. Panels are reproduced from Refs. [94, 179] with permission. Copyright 2015 and 2016 Nature Publishing Group

$\left(\Delta G_{\mathrm{H}^{*}}\right)$ to a more optimal value $\left(\Delta G_{\mathrm{H}^{*}}=-0.01 \mathrm{eV}\right)$, which is even better than the Pt material.

It is worth noting that within the last few years there has been a fast growth in the study fields of SACs. All kinds of noble and non-noble SACs have been fabricated and used as a high activity HER electrocatalysts. Table 2 lists a detailed comparison of their electrochemical HER performances.

\section{Summary and Outlook}

Single-atom catalysts (SACs), with maximum atom-utilization efficiency, exhibit many advantages particularly for HER application with high activity and stability. In recent years, intensive researches have been carried out in this field. In this review, all the important SACs synthetic 

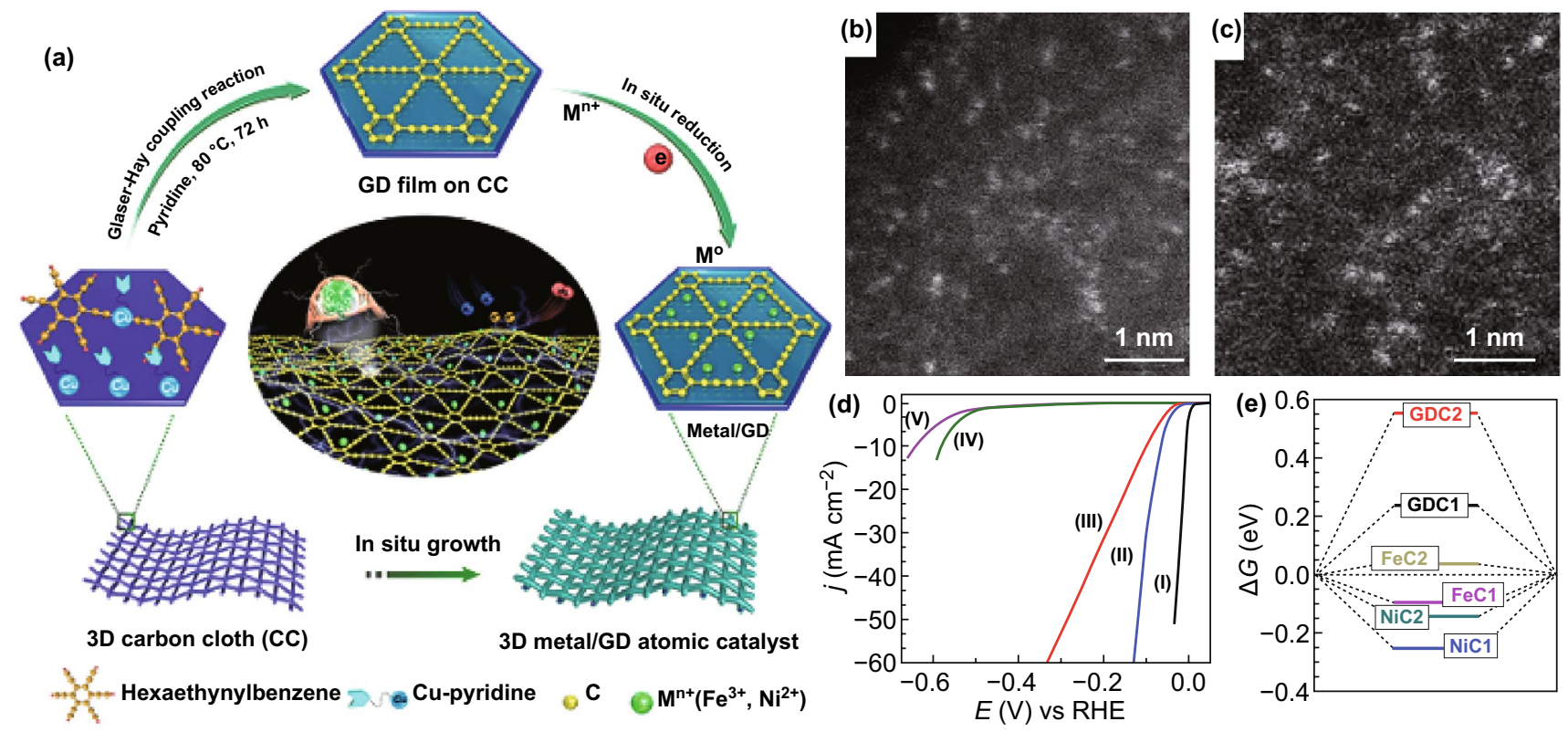

Fig. 15 a Schematic illustration for the synthesis of Fe/GD and Ni/GD. AC-HAADF-STEM images of b Ni/GD and $\mathbf{c}$ Fe/GD. d Polarization curves of $\mathrm{CC}, \mathrm{Ni} / \mathrm{GD}, \mathrm{GDF}, \mathrm{Fe} / \mathrm{GD}$, and Pt/C. e The chemisorption energy of $H$ for HER performance related to the free energy profile $(\Delta G)$. Panels are reproduced from Ref. [155] with permission. Copyright 2018 Nature Publishing Group

strategies reported so far, including the wet-chemistry method, atomic layer deposition (ALD), metal-organic framework (MOF)-derived method, electrodeposition, high-temperature atom trapping from bulk particles, and vacancies/defects immobilized strategy, have been included and discussed in detail. In addition, to reveal the structures and compositions of SACs, various advanced characterization techniques, such as aberration-corrected high-angle annular dark-field scanning transmission electron microscopy (AC-corrected HAADF-STEM), X-ray absorption near-edge structure (XANES), and extended $\mathrm{X}$-ray absorption fine structure (EXAFS) techniques as well as density functional theory (DFT) simulation have also been summarized and discussed. Finally, various metal-based (especially Pt, Pd, Ru, Fe, Co, Ni, Mo, W) SACs in electrocatalytic HER have been systematically reviewed. Despite these significant achievements in the past few years in SACs for electrochemical HER field, there are still challenges in this fascinating field that remain to be resolved:
(1) As it is known, SACs need to be dispersed on support to avoid prevent them from aggregation and at the same time to increase their utilization efficiency during the catalytic reactions. Therefore, supports play an important role in SACs synthesis and their catalytic processes. To this end, more efforts should be devoted to finding new, more conductive and robust support materials.

(2) At present, only Pt, Pd, Ru, Fe, Co, Ni, Mo, W SACs have been investigated in the HER catalytic field. Based on experimental evidence, $\mathrm{V}, \mathrm{Nb}, \mathrm{Ta}, \mathrm{Mn}, \mathrm{Rh}, \mathrm{Ir}, \mathrm{Ag}$, $\mathrm{Au}$, and $\mathrm{Cu}$ metal compounds have also been reported to be potential electrocatalysts for HER. Therefore, research efforts should be extended to more metal SACs for HER.

(3) To investigate the active centers and understand the catalytic reaction mechanism, advanced in situ and ex situ characterization techniques are highly desirable and beneficial for the rational design and observation of high-performance SACs.

(4) DFT simulation is a useful tool in disclosing the catalytic reaction mechanism and predicting the catalyti- 

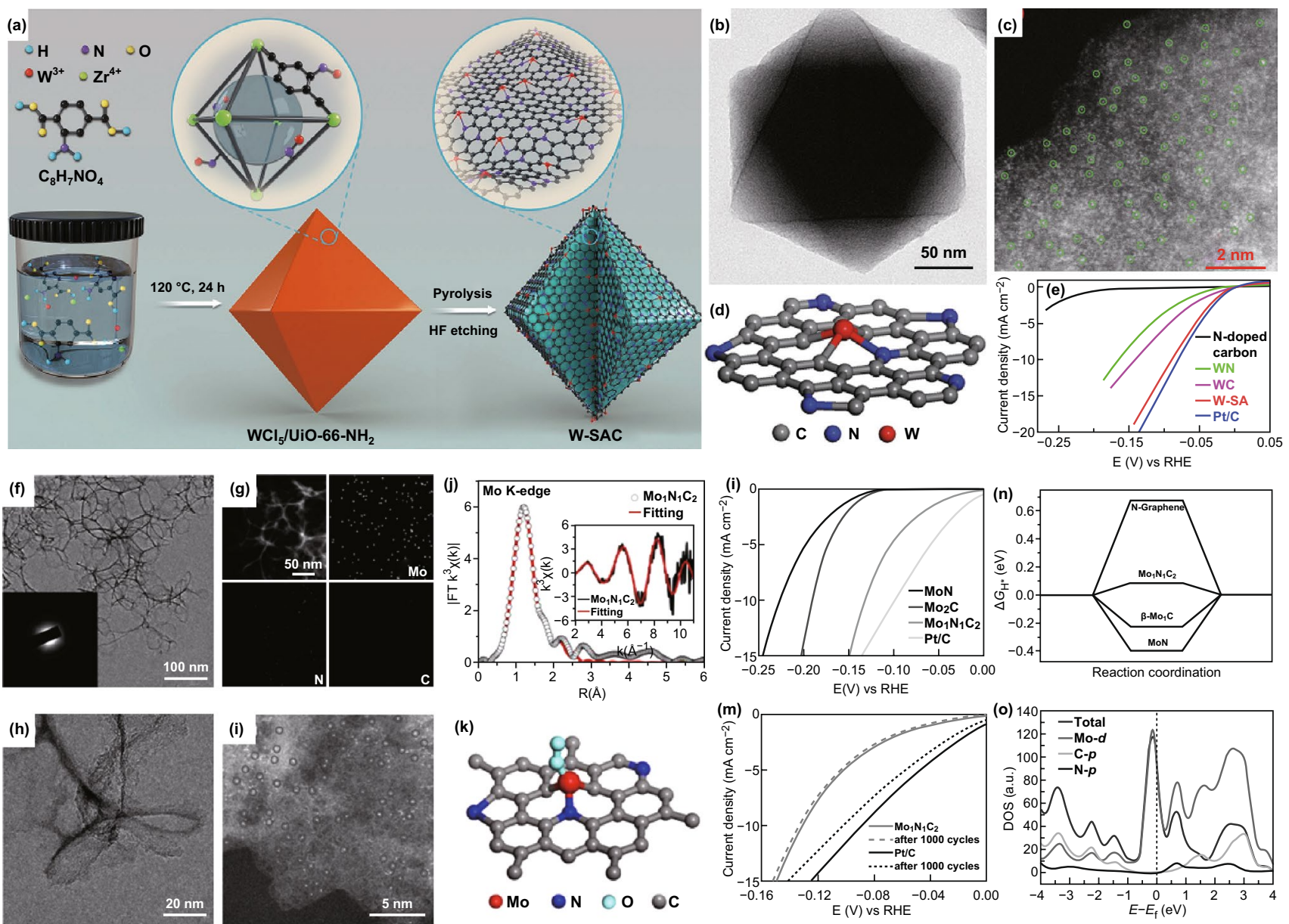

Fig. 16 a The formation process of W SACs. b TEM and c AC-HAADF-STEM images of the W SACs. d Atomic structure model of the W SACs. e Polarization curves for the W SACs. $\mathbf{f}$ TEM image of the $\mathrm{Mo}_{1} \mathrm{~N}_{1} \mathrm{C}_{2}$, the insert is SAED pattern. $\mathbf{g}$ EDS maps for Mo $\mathrm{N}_{1} \mathrm{C}_{2}$ material. $\mathbf{h}$ HRTEM and $\mathbf{i}$ AC-HAADF-STEM images of the $\mathrm{Mo}_{1} \mathrm{~N}_{1} \mathrm{C}_{2}$. j Mo K-edge FT-EXAFS fitting curves of the $\mathrm{Mo}_{1} \mathrm{~N}_{1} \mathrm{C}_{2}$. $\mathbf{k}$ Atomic structure model of the $\mathrm{Mo}_{1} \mathrm{~N}_{1} \mathrm{C}_{2}$. I Polarization curves for the $\mathrm{Mo}_{1} \mathrm{~N}_{1} \mathrm{C}_{2}, \mathrm{MoN}, \mathrm{Mo}_{2} \mathrm{C}$, and 20\% Pt/C. $\mathbf{m}$ Polarization curves for the $\mathrm{Mo}_{1} \mathrm{~N}_{1} \mathrm{C}_{2}$ before and after $1000 \mathrm{CV}$ cycles. $\mathbf{n}$ Gibbs free energy for $H^{*}$ adsorption for $\mathrm{Mo}_{2} \mathrm{C}, \mathrm{Mo}_{1} \mathrm{~N}_{1} \mathrm{C}_{2}$, and $\mathrm{MoN}$. o The calculated DOS of the $\mathrm{Mo}_{1} \mathrm{~N}_{1} \mathrm{C}_{2}$. Panels are reproduced from Refs. [148, 153] with permission. Copyright 2018 and 2017 Wiley-VCH

cally active species. However, accurate assessment of the catalytic centers resulting from SACs electrocatalysts still needs further in-depth study.

(5) Until now, the electrocatalytic behavior of SACs is still ambiguous. Consequently, DFT simulations in combination with XAFS fitting and the experimental data have brought unprecedented insight into the real mechanism.

(6) Although most of SACs exhibit Pt-like or even better than Pt activity toward HER, it should be pointed out that the durability problem is another huge challenge for SACs toward practical application; particularly, in industrial polymer electrolyte membrane (PEM) electrolyzers always need catalysts to maintain high activity and stability over $50,000 \mathrm{~h}$.

Overall, the future directions of SACs development for HER can be focused on developing new and more efficient SACs and their supporting materials, discovering the HER catalytic reaction mechanisms at the molecular scale by a combination of experimental result and DFT calculations, 
Table 2 Summary of the HER activity of SACs in acid/neutral/alkaline solutions

\begin{tabular}{|c|c|c|c|c|}
\hline Catalysts & Electrolytes & $\eta @ j\left(\mathrm{mV} @ \mathrm{~mA}^{-2}\right)$ & Tafel slope $\left(\mathrm{mV} \mathrm{dec}{ }^{-1}\right)$ & References \\
\hline $\mathrm{Pt}-\mathrm{MoS}_{2}$ & $0.1 \mathrm{M} \mathrm{H}_{2} \mathrm{SO}_{4}$ & 150@10 & 96 & [92] \\
\hline ALD50Pt/NGNs & $0.5 \mathrm{M} \mathrm{H}_{2} \mathrm{SO}_{4}$ & $50 @ 16$ & 29 & [52] \\
\hline 400-SWMT/Pt & $0.5 \mathrm{M} \mathrm{H}_{2} \mathrm{SO}_{4}$ & 27@10 & 38 & [93] \\
\hline Pt-GDY2 & $0.5 \mathrm{M} \mathrm{H}_{2} \mathrm{SO}_{4}$ & ５0@30 & 38 & [176] \\
\hline PtSA-NT-NF & $1.0 \mathrm{M}$ PBS & 24@10 & 30 & [53] \\
\hline Pt SAs/DG & $0.5 \mathrm{M} \mathrm{H}_{2} \mathrm{SO}_{4}$ & 23@10 & 25 & [160] \\
\hline $\mathrm{Mo}_{2} \mathrm{TiC}_{2} \mathrm{~T}_{x}-\mathrm{Pt}_{\mathrm{SA}}$ & $0.5 \mathrm{M} \mathrm{H}_{2} \mathrm{SO}_{4}$ & $30 @ 10$ & 30 & [161] \\
\hline Pt@PCM & $0.5 \mathrm{M} \mathrm{H}_{2} \mathrm{SO}_{4}$ & 105@10 & 65.3 & {$[175]$} \\
\hline $\mathrm{Pt} @ \mathrm{PCM}$ & $1.0 \mathrm{M} \mathrm{KOH}$ & 139@10 & 73.6 & {$[175]$} \\
\hline $\mathrm{Pt}_{1}-\mathrm{MoO}_{3-x}$ & $0.5 \mathrm{M} \mathrm{H}_{2} \mathrm{SO}_{4}$ & 23.3@10 & 28.8 & {$[185]$} \\
\hline Pt SASs/AG & $0.5 \mathrm{M} \mathrm{H}_{2} \mathrm{SO}_{4}$ & 12@10 & 29.33 & [186] \\
\hline SANi-PtNWs & $1.0 \mathrm{M} \mathrm{KOH}$ & 70@10 & 60.3 & [187] \\
\hline Pt1/NMC & $0.5 \mathrm{M} \mathrm{H}_{2} \mathrm{SO}_{4}$ & $55 @ 100$ & 26 & [188] \\
\hline $\mathrm{Pt} / \mathrm{np}-\mathrm{Co}_{0.85} \mathrm{Se}$ & $1.0 \mathrm{M}$ PBS & $55 @ 10$ & 35 & [189] \\
\hline $\mathrm{Pd}-\mathrm{MoS}_{2}$ & $0.5 \mathrm{M} \mathrm{H}_{2} \mathrm{SO}_{4}$ & 78@10 & 62 & [177] \\
\hline $\mathrm{Pd} / \mathrm{Cu}-\mathrm{Pt} \mathrm{NRs}$ & $0.5 \mathrm{M} \mathrm{H}_{2} \mathrm{SO}_{4}$ & 22.8@10 & 25 & [190] \\
\hline RuSAs@PN & $0.5 \mathrm{M} \mathrm{H}_{2} \mathrm{SO}_{4}$ & 24@10 & 38 & [126] \\
\hline Ru@Co SAs/N-C & $1.0 \mathrm{M} \mathrm{KOH}$ & $7 @ 10$ & 30 & [191] \\
\hline $\mathrm{Ru}-\mathrm{MoS}_{2} / \mathrm{CC}$ & $1.0 \mathrm{M} \mathrm{KOH}$ & $41 @ 10$ & 114 & [192] \\
\hline $\mathrm{Pt}-\mathrm{Ru}$ dimer & $0.5 \mathrm{M} \mathrm{H}_{2} \mathrm{SO}_{4}$ & 20@10 & 28.9 & [193] \\
\hline $\mathrm{Fe} / \mathrm{GD}$ & $0.5 \mathrm{M} \mathrm{H}_{2} \mathrm{SO}_{4}$ & 66@10 & 37.8 & [155] \\
\hline $\mathrm{Ni} / \mathrm{GD}$ & $0.5 \mathrm{M} \mathrm{H}_{2} \mathrm{SO}_{4}$ & 88@10 & 45.8 & {$[155]$} \\
\hline $\mathrm{A}-\mathrm{Ni}-\mathrm{C}$ & $0.5 \mathrm{M} \mathrm{H}_{2} \mathrm{SO}_{4}$ & 34@10 & 41 & [179] \\
\hline Ni-doped graphene & $0.5 \mathrm{M} \mathrm{H}_{2} \mathrm{SO}_{4}$ & 180@10 & 45 & {$[180]$} \\
\hline A-Ni@DG & $0.5 \mathrm{M} \mathrm{H}_{2} \mathrm{SO}_{4}$ & 70@10 & 31 & [184] \\
\hline SANi-I & $1.0 \mathrm{M} \mathrm{KOH}$ & 60@100 & 34.6 & [194] \\
\hline $\mathrm{Co}-\mathrm{NG}$ & $0.5 \mathrm{M} \mathrm{H}_{2} \mathrm{SO}_{4}$ & 147@10 & 82 & [94] \\
\hline $\mathrm{Co}_{1} / \mathrm{PCN}$ & $1.0 \mathrm{M} \mathrm{KOH}$ & 138@10 & 52 & {$[182]$} \\
\hline Co SAs/PTF-600 & $0.5 \mathrm{M} \mathrm{H}_{2} \mathrm{SO}_{4}$ & 94@10 & 50 & [195] \\
\hline $\mathrm{Mo}_{1} \mathrm{~N}_{1} \mathrm{C}_{2}$ & $0.5 \mathrm{M} \mathrm{H}_{2} \mathrm{SO}_{4}$ & 154@10 & 86 & [153] \\
\hline $\mathrm{W}_{1} \mathrm{~N}_{1} \mathrm{C}_{3}$ & $0.5 \mathrm{M} \mathrm{H}_{2} \mathrm{SO}_{4}$ & 105@10 & 58 & {$[148]$} \\
\hline
\end{tabular}

and exploring new SACs for HER and their structural analysis.

Acknowledgements This work was financially supported by the Natural Sciences and Engineering Research Council of Canada (NSERC), Institut National de la Recherche Scientifique (INRS), and the National Natural Science Foundation of China (516722040).

Open Access This article is licensed under a Creative Commons Attribution 4.0 International License, which permits use, sharing, adaptation, distribution and reproduction in any medium or format, as long as you give appropriate credit to the original author(s) and the source, provide a link to the Creative Commons licence, and indicate if changes were made. The images or other third party material in this article are included in the article's Creative Commons licence, unless indicated otherwise in a credit line to the material. If material is not included in the article's Creative Commons licence and your intended use is not permitted by statutory regulation or exceeds the permitted use, you will need to obtain permission directly from the copyright holder. To view a copy of this licence, visit http://creativecommons.org/licenses/by/4.0/.

\section{References}

1. B. Dunn, H. Kamath, J.-M. Tarascon, Electrical energy storage for the grid: a battery of choices. Science 334(6058), 928-935 (2011). https://doi.org/10.1126/science.1212741 
2. M. Armand, J.M. Tarascon, Building better batteries. Nature 451(7179), 652-657 (2008). https://doi.org/10.1038/451652a

3. J.A. Turner, Sustainable hydrogen production. Science 305(5686), 972-974 (2004). https://doi.org/10.1126/scien ce. 1103197

4. A.S. Arico, P. Bruce, B. Scrosati, J.M. Tarascon, W. Van Schalkwijk, Nanostructured materials for advanced energy conversion and storage devices. Nat. Mater. 4, 366-377 (2005). https://doi.org/10.1142/9789814317665_0022

5. P.G. Bruce, S.A. Freunberger, L.J. Hardwick, J.M. Tarascon, $\mathrm{Li}-\mathrm{O}_{2}$ and $\mathrm{Li}-\mathrm{S}$ batteries with high energy storage. Nat. Mater. 11(1), 19-29 (2012). https://doi.org/10.1038/ nmat3191

6. L. Liao, Q. Zhang, Z. Su, Z. Zhao, Y. Wang et al., Efficient solar water-splitting using a nanocrystalline $\mathrm{CoO}$ photocatalyst. Nat. Nanotechnol. 9(1), 69-73 (2013). https://doi. org/10.1038/nnano.2013.272

7. Y. Fu, Q. Wei, G. Zhang, S. Sun, Batteries: advanced phosphorus-based materials for lithium/sodium-ion batteries: recent developments and future perspectives. Adv. Energy Mater. 8(13), 1702849 (2018). https://doi.org/10.1002/ aenm.201702849

8. D.A. Rand, R.M. Dell, Hydrogen Energy: Challenges and Prospects (RSC Publishing, Cambridge, 2007)

9. S. Dunn, Hydrogen futures: toward a sustainable energy system. Int. J. Hydrogen Energy 27(3), 235-264 (2002). https://doi.org/10.1016/S0360-3199(01)00131-8

10. J. Turner, G. Sverdrup, M.K. Mann, P.C. Maness, B. Kroposki, M. Ghirardi, R.J. Evans, D. Blake, Renewable hydrogen production. Int. J. Energy Res. 32(5), 379-407 (2008). https://doi.org/10.1002/er.1372

11. Z. Pu, I.S. Amiinu, Z. Kou, W. Li, S. Mu, RuP 2 -based catalysts with platinum-like activity and higher durability for the hydrogen evolution reaction at all $\mathrm{pH}$ values. Angew. Chem. Int. Ed. 56(38), 11559-11564 (2017). https://doi. org/10.1002/anie.201704911

12. J. Wang, W. Cui, Q. Liu, Z. Xing, A.M. Asiri, X. Sun, Recent progress in cobalt-based heterogeneous catalysts for electrochemical water splitting. Adv. Mater. 28(2), 215-230 (2016). https://doi.org/10.1002/adma.201502696

13. L. Feng, G. Yu, Y. Wu, G. Li, H. Li et al., High-index faceted $\mathrm{Ni}_{3} \mathrm{~S}_{2}$ nanosheet arrays as highly active and ultrastable electrocatalysts for water splitting. J. Am. Chem. Soc. 137(44), 14023-14026 (2015). https://doi.org/10.1021/ jacs.5b08186

14. X. Zou, Y. Zhang, Noble metal-free hydrogen evolution catalysts for water splitting. Chem. Soc. Rev. 44(15), 51485180 (2015). https://doi.org/10.1039/C4CS00448E

15. Y. Yan, B. Yu Xia, B. Zhao, X. Wang, A review on noblemetal-free bifunctional heterogeneous catalysts for overall electrochemical water splitting. J. Mater. Chem. A 4(45), 17587-17603 (2016). https://doi.org/10.1039/C6TA0 $8075 \mathrm{H}$

16. S. Anantharaj, S.R. Ede, K. Sakthikumar, K. Karthick, S. Mishra, S. Kundu, Recent trends and perspectives in electrochemical water splitting with an emphasis on sulfide, selenide, and phosphide catalysts of $\mathrm{Fe} \mathrm{Co}$, and $\mathrm{Ni}$ : a review. ACS Catal. 6(12), 8069-8097 (2016). https://doi. org/10.1021/acscatal.6b02479

17. M.G. Walter, E.L. Warren, J.R. McKone, S.W. Boettcher, Q. Mi, E.A. Santori, N.S. Lewis, Solar water splitting cells. Chem. Rev. 110(11), 6446-6473 (2010). https://doi. org/10.1021/cr1002326

18. A.J. Bard, M.A. Fox, Artificial photosynthesis: solar splitting of water to hydrogen and oxygen. Acc. Chem. Res. 28(3), 141-145 (1995). https://doi.org/10.1021/ar00051a007

19. M.S. Faber, S. Jin, Earth-abundant inorganic electrocatalysts and their nanostructures for energy conversion applications. Energy Environ. Sci. 7(11), 3519-3542 (2014). https://doi. org/10.1039/C4EE01760A

20. C. Tang, N. Cheng, Z. Pu, W. Xing, X. Sun, NiSe nanowire film supported on nickel foam: an efficient and stable 3D bifunctional electrode for full water splitting. Angew. Chem. Int. Ed. 54(32), 9483-9487 (2015). https://doi.org/10.1002/ anie. 201503407

21. Q. Luo, M. Peng, X. Sun, Y. Luo, A.M. Asiri, Efficient electrochemical water splitting catalyzed by electrodeposited $\mathrm{NiFe}$ nanosheets film. Int. J. Hydrogen Energy 41(21), 87858792 (2016). https://doi.org/10.1016/j.ijhydene.2016.04.007

22. L. Stern, L. Feng, F. Song, X. Hu, $\mathrm{Ni}_{2} \mathrm{P}$ as a Janus catalyst for water splitting: the oxygen evolution activity of $\mathrm{Ni}_{2} \mathrm{P}$ nanoparticles. Energy Environ. Sci. 8, 2347-2351 (2015). https:// doi.org/10.1039/C5EE01155H

23. Z. Pu, Y. Luo, A.M. Asiri, X. Sun, Efficient electrochemical water splitting catalyzed by electrodeposited nickel diselenide nanoparticles based film. ACS Appl. Mater. Interfaces 8(7), 4718-4723 (2016). https://doi.org/10.1021/acsami.5b12143

24. J. Zhang, T. Wang, D. Pohl, B. Rellinghaus, R. Dong, S. Liu, $X$. Zhuang, X. Feng, Interface engineering of $\mathrm{MoS}_{2} / \mathrm{Ni}_{3} \mathrm{~S}_{2}$ heterostructures for highly enhanced electrochemical overall-water-splitting activity. Angew. Chem. Int. Ed. 55(23), 6814-6819 (2016). https://doi.org/10.1002/anie.201602237

25. J. Zhang, L. Dai, Nitrogen, phosphorus, and fluorine tri-doped graphene as a multifunctional catalyst for self-powered electrochemical water splitting. Angew. Chem. Int. Ed. 55(42), 13296-13300 (2016). https://doi.org/10.1002/anie.20160 7405

26. T. Reier, Z. Pawolek, S. Cherevko, M. Bruns, T. Jones et al., Molecular insight in structure and activity of highly efficient, low-Ir Ir-Ni oxide catalysts for electrochemical water splitting (OER). J. Am. Chem. Soc. 137(40), 13031-13040 (2015). https://doi.org/10.1021/jacs.5b07788

27. Y. Tan, H. Wang, P. Liu, Y. Shen, C. Cheng et al., Versatile nanoporous bimetallic phosphides towards electrochemical water splitting. Energy Environ. Sci. 7, 2257-2261 (2016). https://doi.org/10.1039/C6EE01109H

28. J. Masa, P. Weide, D. Peeters, I. Sinev, W. Xia et al., Amorphous cobalt boride $\left(\mathrm{Co}_{2} \mathrm{~B}\right)$ as a highly efficient nonprecious catalyst for electrochemical water splitting: oxygen and hydrogen evolution. Adv. Energy Mater. 6(6), 1502313 (2016). https://doi.org/10.1002/aenm.201502313 
29. Y. Shi, B. Zhang, Recent advances in transition metal phosphide nanomaterials: synthesis and applications in hydrogen evolution reaction. Chem. Soc. Rev. 45(6), 1529-1541 (2016). https://doi.org/10.1039/C5CS00434A

30. Y. Zheng, Y. Jiao, M. Jaroniec, S. Qiao, Advancing the electrochemistry of the hydrogen-evolution reaction through combining experiment and theory. Angew. Chem. Int. Ed. 54(1), 52-65 (2015). https://doi.org/10.1002/anie.201407031

31. E.J. Popczun, J.R. McKone, C.G. Read, A.J. Biacchi, A.M. Wiltrout, N.S. Lewis, R.E. Schaak, Nanostructured nickel phosphide as an electrocatalyst for the hydrogen evolution reaction. J. Am. Chem. Soc. 135(25), 9267-9270 (2013). https://doi.org/10.1021/ja403440e

32. Y. Li, H. Wang, L. Xie, Y. Liang, G. Hong, H. Dai, $\mathrm{MoS}_{2}$ nanoparticles grown on graphene: an advanced catalyst for the hydrogen evolution reaction. J. Am. Chem. Soc. 133(19), 7296-7299 (2011). https://doi.org/10.1021/ja201269b

33. C. Tang, L. Gan, R. Zhang, W. Lu, X. Jiang, A.M. Asiri, X. Sun, J. Wang, L. Chen, Ternary $\mathrm{Fe}_{x} \mathrm{Co}_{1-x} \mathrm{P}$ nanowire array as a robust hydrogen evolution reaction electrocatalyst with Ptlike activity: experimental and theoretical insight. Nano Lett. 16(10), 6617-6621 (2016). https://doi.org/10.1021/acs.nanol ett.6b03332

34. Z. Pu, Q. Liu, P. Jiang, A.M. Asiri, A.Y. Obaid, X. Sun, CoP nanosheet arrays supported on a Ti plate: an efficient cathode for electrochemical hydrogen evolution. Chem. Mater. 26(15), 4326-4329 (2014). https://doi.org/10.1021/cm501 273s

35. Y. Zheng, Y. Jiao, Y. Zhu, L. Li, Y. Han et al., Hydrogen evolution by a metal-free electrocatalyst. Nat. Commun. 5, 3783 (2014). https://doi.org/10.1038/ncomms4783

36. D. Kong, J.J. Cha, H. Wang, H.R. Lee, Y. Cui, First-row transition metal dichalcogenide catalysts for hydrogen evolution reaction. Energy Environ. Sci. 6(12), 3553-3558 (2013). https://doi.org/10.1039/C3EE42413H

37. J. Kibsgaard, T.F. Jaramillo, Molybdenum phosphosulfide: an active, acid-stable, earth-abundant catalyst for the hydrogen evolution reaction. Angew. Chem. Int. Ed. 53(52), 1443314437 (2014). https://doi.org/10.1002/anie.201408222

38. I. Bhugun, D. Lexa, J.M. Savéant, Homogeneous catalysis of electrochemical hydrogen evolution by iron(0) porphyrins. J. Am. Chem. Soc. 118(16), 3982-3983 (1996). https://doi. org/10.1021/ja954326x

39. D. Kong, H. Wang, Z. Lu, Y. Cui, $\mathrm{CoSe}_{2}$ nanoparticles grown on carbon fiber paper: an efficient and stable electrocatalyst for hydrogen evolution reaction. J. Am. Chem. Soc. 136(13), 4897-4900 (2014). https://doi.org/10.1021/ja501497n

40. J.R. McKone, B.F. Sadtler, C.A. Werlang, N.S. Lewis, H.B. Gray, Ni-Mo nanopowders for efficient electrochemical hydrogen evolution. ACS Catal. 3(2), 166-169 (2013). https ://doi.org/10.1021/cs300691m

41. R. Subbaraman, D. Tripkovic, D. Strmcnik, K.C. Chang, M. Uchimura, A.P. Paulikas, V. Stamenkovic, N.M. Markovic, Enhancing hydrogen evolution activity in water splitting by tailoring $\mathrm{Li}^{+}-\mathrm{Ni}(\mathrm{OH})_{2}-\mathrm{Pt}$ interfaces. Science 334(6060), 1256-1260 (2011). https://doi.org/10.1126/science.1211934
42. T. Chao, X. Luo, W. Chen, B. Jiang, J. Ge, Y. Lin, G. Wu, X. Wang, Y. Hu, Z. Zhuang, Y. Wu, X. Hong, Y. Li, Atomically dispersed copper-platinum dual sites alloyed with palladium nanorings catalyze the hydrogen evolution reaction. Angew. Chem. Int. Ed. 56(50), 16263-16267 (2017). https://doi. org/10.1002/anie.201709803

43. S. Sarkar, S.C. Peter, An overview on Pd-based electrocatalysts for the hydrogen evolution reaction. Inorg. Chem. Front. 5(9), 2060-2080 (2018). https://doi.org/10.1039/ C8QI00042E

44. G. Xu, J. Hui, T. Huang, Y. Chen, J.M. Lee, Platinum nanocuboids supported on reduced graphene oxide as efficient electrocatalyst for the hydrogen evolution reaction. J. Power Sources 285, 393-399 (2015). https://doi.org/10.1016/j. jpowsour.2015.03.131

45. Y. Mi, L. Wen, Z. Wang, D. Cao, H. Zhao, Y. Zhou, F. Grote, Y. Leia, Ultra-low mass loading of platinum nanoparticles on bacterial cellulose derived carbon nanofibers for efficient hydrogen evolution. Catal. Today 262, 141-145 (2016). https://doi.org/10.1016/j.cattod.2015.08.019

46. C. Tang, D. Wang, Z. Wu, B. Duan, Tungsten carbide hollow microspheres as electrocatalyst and platinum support for hydrogen evolution reaction. Int. J. Hydrogen Energy 40(8), 3229-3237 (2015). https://doi.org/10.1016/j.ijhyd ene.2014.12.105

47. H. Yin, S. Zhao, K. Zha, A. Muqsit, H. Tang et al., Ultrathin platinum nanowires grown on single-layered nickel hydroxide with high hydrogen evolution activity. Nat. Commun. 6, 6430 (2015). https://doi.org/10.1038/ncomms7430

48. Z. Xing, C. Han, D. Wang, Q. Li, X. Yang, Ultrafine Pt nanoparticle-decorated $\mathrm{Co}(\mathrm{OH})_{2}$ nanosheet arrays with enhanced catalytic activity toward hydrogen evolution. ACS Catal. 7(10), 7131-7135 (2017). https://doi.org/10.1021/ acscatal.7b01994

49. R. Huang, Z. Sun, S. Chen, S. Wu, Z. Shen, X. Wu, J. Zeng, $\mathrm{Pt}-\mathrm{Cu}$ hierarchical quasi great dodecahedrons with abundant twinning defects for hydrogen evolution. Chem. Commun. 53(51), 6922-6925 (2017). https://doi.org/10.1039/ C7CC03643D

50. Y. Shen, A.C. Lua, J. Xi, X. Qiu, Ternary platinum-copper-nickel nanoparticles anchored to hierarchical carbon supports as free-standing hydrogen evolution electrodes. ACS Appl. Mater. Interfaces 8(5), 3464-3472 (2016). https ://doi.org/10.1021/acsami.5b11966

51. P. Wang, X. Zhang, J. Zhang, S. Wan, S. Guo, G. Lu, J. Yao, X. Huang, Precise tuning in platinum-nickel/nickel sulfide interface nanowires for synergistic hydrogen evolution catalysis. Nat. Commun. 8, 14580 (2017). https://doi. org/10.1038/ncomms 14580

52. N. Cheng, S. Stambula, D. Wang, M.N. Banis, J. Liu et al., Platinum single-atom and cluster catalysis of the hydrogen evolution reaction. Nat. Commun. 7, 13638 (2016). https ://doi.org/10.1038/ncomms 13638

53. L. Zhang, L. Han, H. Liu, X. Liu, J. Luo, Potential-cycling synthesis of single platinum atoms for efficient hydrogen evolution in neutral media. Angew. Chem. Int. Ed. 56(44), 
13694-13698 (2017). https://doi.org/10.1002/anie.20170 6921

54. Y. Lee, J. Suntivich, K.J. May, E.E. Perry, Y. Shao-Horn, Synthesis and activities of rutile $\mathrm{IrO}_{2}$ and $\mathrm{RuO}_{2}$ nanoparticles for oxygen evolution in acid and alkaline solutions. J. Phys. Chem. Lett. 3(3), 399-404 (2012). https://doi. org/10.1021/jz2016507

55. J. Zhang, L. Qu, G. Shi, J. Liu, J. Chen, L. Dai, N, P-codoped carbon networks as efficient metal-free bifunctional catalysts for oxygen reduction and hydrogen evolution reactions. Angew. Chem. Int. Ed. 55(6), 2230-2234 (2016). https://doi. org/10.1002/anie.201510495

56. L. He, Y. Huang, A. Wang, X. Wang, X. Chen, J.J. Delgado, T. Zhang, A noble-metal-free catalyst derived from Ni-Al hydrotalcite for hydrogen generation from $\mathrm{N}_{2} \mathrm{H}_{4} \cdot \mathrm{H}_{2} \mathrm{O}$ decomposition. Angew. Chem. Int. Ed. 51(25), 6191-6194 (2012). https://doi.org/10.1002/anie.201201737

57. E.J. Popczun, C.G. Read, C.W. Roske, N.S. Lewis, R.E. Schaak, Highly active electrocatalysis of the hydrogen evolution reaction by cobalt phosphide nanoparticles. Angew. Chem. Int. Ed. 53(21), 5427-5430 (2014). https://doi. org/10.1002/anie.201402646

58. J. Tian, Q. Liu, A.M. Asiri, X. Sun, Self-supported nanoporous cobalt phosphide nanowire arrays: an efficient $3 \mathrm{D}$ hydrogen-evolving cathode over the wide range of $\mathrm{pH} 0-14$. J. Am. Chem. Soc. 136(21), 7587-7590 (2014). https://doi. org/10.1021/ja503372r

59. W. Cui, N. Cheng, Q. Liu, C. Ge, A.M. Asiri, X. Sun, $\mathrm{Mo}_{2} \mathrm{C}$ nanoparticles decorated graphitic carbon sheets: biopolymerderived solid-state synthesis and application as an efficient electrocatalyst for hydrogen generation. ACS Catal. 4(8), 2658-2661 (2014). https://doi.org/10.1021/cs5005294

60. Y. Xu, M. Gao, Y. Zheng, J. Jiang, S. Yu, Nickel/Nickel(II) oxide nanoparticles anchored onto cobalt(IV) diselenide nanobelts for the electrochemical production of hydrogen. Angew. Chem. Int. Ed. 52(33), 8546-8550 (2013). https:// doi.org/10.1002/anie.201303495

61. X. Wang, K. Maeda, A. Thomas, K. Takanabe, G. Xin, J.M. Carlsson, K. Domen, M. Antonietti, A metal-free polymeric photocatalyst for hydrogen production from water under visible light. Nat. Mater. 8(1), 76-80 (2009). https://doi. org/10.1038/nmat2317

62. A.L. Goff, V. Artero, B. Jousselme, P.D. Tran, N. Guillet et al., From hydrogenases to noble metal-free catalytic nanomaterials for $\mathrm{H}_{2}$ production and uptake. Science 326(5958), 1384-1387 (2009). https://doi.org/10.1126/science.1179773

63. W. Chen, J.T. Muckerman, E. Fujita, Recent developments in transition metal carbides and nitrides as hydrogen evolution electrocatalysts. Chem. Commun. 49(79), 8896-8909 (2013). https://doi.org/10.1039/C3CC44076A

64. Q. Liu, J. Tian, W. Cui, N. Cheng, A.M. Asiri, X. Sun, Carbon nanotubes decorated with CoP nanocrystals: a highly active non-noble-metal nanohybrid electrocatalyst for hydrogen evolution. Angew. Chem. Int. Ed. 53(26), 6710-6714 (2014). https://doi.org/10.1002/anie.201404161
65. P. Jiang, Q. Liu, Y. Liang, J. Tian, A.M. Asiri, X. Sun, A cost-effective 3D hydrogen evolution cathode with high catalytic activity: FeP nanowire array as the active phase. Angew. Chem. Int. Ed. 53(47), 12855-12859 (2014). https ://doi.org/10.1002/anie.201406848

66. C.G. Morales-Guio, X. Hu, Amorphous molybdenum sulfides as hydrogen evolution catalysts. Acc. Chem. Res. 47(8), 2671-2681 (2014). https://doi.org/10.1021/ar5002022

67. B. Cao, G.M. Veith, J.C. Neuefeind, R.R. Adzic, P.G. Khalifah, Mixed close-packed cobalt molybdenum nitrides as non-noble metal electrocatalysts for the hydrogen evolution reaction. J. Am. Chem. Soc. 135(51), 19186-19192 (2013). https://doi.org/10.1021/ja4081056

68. Y. Zhao, F. Zhao, X. Wang, C. Xu, Z. Zhang, G. Shi, L. $\mathrm{Qu}$, Graphitic carbon nitride nanoribbons: graphene-assisted formation and synergic function for highly efficient hydrogen evolution. Angew. Chem. Int. Ed. 53(50), 13934-13939 (2014). https://doi.org/10.1002/anie.201409080

69. I.S. Amiinu, Z. Pu, X. Liu, K.A. Owusu, H.G. Monestel, F.O. Boakye, H. Zhang, S. Mu, Multifunctional Mo-N/C@ $\mathrm{MoS}_{2}$ electrocatalysts for HER, OER, ORR, and $\mathrm{Zn}$-air batteries. Adv. Funct. Mater. 27(44), 1702300 (2017). https:// doi.org/10.1002/adfm.201702300

70. R. Adhikari, K. Basu, Y. Zhou, F. Vetrone, D. Ma et al., Heterostructured quantum dot architectures for efficient and stable photoelectrochemical hydrogen production. J. Mater. Chem. A 6(16), 6822-6829 (2018). https://doi.org/10.1039/ C7TA11378A

71. X.Y. Yu, Y. Feng, Y. Jeon, B.Y. Guan, X.W. Lou, U. Paik, Formation of Ni-Co-MoS ${ }_{2}$ nanoboxes with enhanced electrocatalytic activity for hydrogen evolution. Adv. Mater. 28(40), 9006-9011 (2016). https://doi.org/10.1002/adma.201601188

72. F.X. Ma, H.B. Wu, B.Y. Xia, C.Y. Xu, X.W. Lou, Hierarchical $\beta-\mathrm{Mo}_{2} \mathrm{C}$ nanotubes organized by ultrathin nanosheets as a highly efficient electrocatalyst for hydrogen production. Angew. Chem. Int. Ed. 54(51), 15395-15399 (2015). https:// doi.org/10.1002/anie.201508715

73. L. Liu, A. Corma, Metal catalysts for heterogeneous catalysis: from single atoms to nanoclusters and nanoparticles. Chem. Rev. 118(10), 4981-5079 (2018). https://doi.org/10.1021/acs. chemrev.7b00776

74. S.X. Liang, C. Hao, Y.T. Shi, The power of single-atom catalysis. ChemCatChem 7(17), 2559-2567 (2015). https:// doi.org/10.1002/cctc. 201500363

75. J. Kim, H.E. Kim, H. Lee, Single-atom catalysts of precious metals for electrochemical reactions. ChemSusChem 11(1), 104-113 (2018). https://doi.org/10.1002/cssc.201701306

76. X.F. Yang, A. Wang, B. Qiao, J. Li, J. Liu, T. Zhang, Single-atom catalysts: a new frontier in heterogeneous catalysis. Acc. Chem. Res. 46(8), 1740-1748 (2013). https://doi. org/10.1021/ar300361m

77. B.T. Qiao, A.Q. Wang, X.F. Yang, L.F. Allard, Z. Jiang et al., Single-atom catalysis of $\mathrm{CO}$ oxidation using $\mathrm{Pt}_{1} / \mathrm{FeO}_{x}$. Nat. Chem. 3(8), 634-641 (2011). https://doi.org/10.1038/nchem .1095 
78. B. Bayatsarmadi, Y. Zheng, A. Vasileff, S.Z. Qiao, Recent advances in atomic metal doping of carbon-based nanomaterials for energy conversion. Small 13(21), 1700191 (2017). https://doi.org/10.1002/smll.201700191

79. A. Wang, J. Li, T. Zhang, Heterogeneous single-atom catalysis. Nat. Rev. Chem. 2, 65-81 (2018). https://doi.org/10.1038/ s41570-018-0010-1

80. L.Q. Wang, L. Huang, F. Liang, S.M. Liu, Y.H. Wang, H.J. Zhang, Preparation, characterization and catalytic performance of single-atom catalysts. Chin. J. Catal. 38(9), 15281539 (2017). https://doi.org/10.1016/S1872-2067(17)62770 $-0$

81. C. Liu, Q. Li, C. Wu, J. Zhang, Y. Jin, D.R. MacFarlane, C. Sun, Single-boron catalysts for nitrogen reduction reaction. J. Am. Chem. Soc. 141(7), 2884-2888 (2019). https://doi. org/10.1021/jacs.8b13165

82. J. Su, R. Ge, Y. Dong, F. Hao, L. Chen, Recent progress in single-atom electrocatalysts: concept, synthesis, and applications in clean energy conversion. J. Mater. Chem. A 6(29), 14025-14042 (2018). https://doi.org/10.1039/C8TA04064H

83. A. Corma, P. Concepcion, M. Boronat, M.J. Sabater, J. Navas et al., Exceptional oxidation activity with size-controlled supported gold clusters of low atomicity. Nat. Chem. 5(9), 775-781 (2013). https://doi.org/10.1038/nchem.1721

84. P. Liu, Y. Zhao, R. Qin, S. Mo, G. Chen et al., Photochemical route for synthesizing atomically dispersed palladium catalysts. Science 352(6287), 797-801 (2016). https://doi. org/10.1126/science.aaf5251

85. R. Lang, T. Li, D. Matsumura, S. Miao, Y. Ren et al., Hydroformylation of olefins by a rhodium single-atom catalyst with activity comparable to $\mathrm{RhCl}\left(\mathrm{PPh}_{3}\right)_{3}$. Angew. Chem. Int. Ed. 55(52), 16054-16058 (2016). https://doi.org/10.1002/ anie. 201607885

86. F. Chen, X. Jiang, L. Zhang, R. Lang, B. Qiao, Singleatom catalysis: bridging the homo-and heterogeneous catalysis. Chin. J. Catal. 39(5), 893-898 (2018). https://doi. org/10.1016/S1872-2067(18)63047-5

87. J. Yang, D. He, W. Chen, W. Zhu, H. Zhang et al., Bimetallic $\mathrm{Ru}-\mathrm{Co}$ clusters derived from a confined alloying process within zeolite-imidazolate frameworks for efficient $\mathrm{NH}_{3}$ decomposition and synthesis. ACS Appl. Mater. Interfaces 9(45), 39450-39455 (2017). https://doi.org/10.1021/acsam i.7b14134

88. S. Tian, Q. Fu, W. Chen, Q. Feng, Z. Chen et al., Carbon nitride supported $\mathrm{Fe}_{2}$ cluster catalysts with superior performance for alkene epoxidation. Nat. Commun. 9(1), 2353 (2018). https://doi.org/10.1038/s41467-018-04845-X

89. X. Dai, Z. Chen, T. Yao, L. Zheng, Y. Lin et al., Single Ni sites distributed on N-doped carbon for selective hydrogenation of acetylene. Chem. Commun. 53(84), 11568 (2017). https://doi.org/10.1039/C7CC04820C

90. T. Chao, Y. Hu, X. Hong, Y. Li, Design of noble metal electrocatalysts on an atomic level. ChemElectroChem 6(2), 289-303 (2019). https://doi.org/10.1002/celc.201801189

91. S.T. Hunt, M. Milina, Z. Wang, Y. Román-Leshkov, Activating earth-abundant electrocatalysts for efficient, low-cost hydrogen evolution/oxidation: sub-monolayer platinum coatings on titanium tungsten carbide nanoparticles. Energy Environ. Sci. 9(10), 3290-3301 (2016). https://doi.org/10.1039/ C6EE01929C

92. J. Deng, H.B. Li, J.P. Xiao, Y.C. Tu, D.H. Deng et al., Triggering the electrocatalytic hydrogen evolution activity of the inert two-dimensional $\mathrm{MoS}_{2}$ surface via single-atom metal doping. Energy Environ. Sci. 8(5), 1594-1601 (2015). https ://doi.org/10.1039/C5EE00751H

93. M. Tavakkoli, N. Holmberg, R. Kronberg, H. Jiang, J. Sainio, E.I. Kauppinen, T. Kallio, K. Laasonen, Electrochemical activation of single-walled carbon nanotubes with pseudoatomic-scale platinum for the hydrogen evolution reaction. ACS Catal. 7(5), 3121-3130 (2017). https://doi.org/10.1021/ acscatal.7b00199

94. H. Fei, J. Dong, M.J. Arellano-Jimenez, G. Ye, N. Dong Kim, E.L. Samuel et al., Atomic cobalt on nitrogen-doped graphene for hydrogen generation. Nat. Commun. 6, 8668 (2015). https://doi.org/10.1038/ncomms9668

95. X.J. Zeng, J.L. Shui, X.F. Liu, Q.T. Liu, Y.C. Li, J.X. Shang, L.R. Zheng, R.H. Yu, Single-atom to single-atom grafting of $\mathrm{Pt}_{1}$ onto $\mathrm{Fe}-\mathrm{N}_{4}$ center: $\mathrm{Pt}_{1} @ \mathrm{Fe}-\mathrm{N}-\mathrm{C}$ multifunctional electrocatalyst with significantly enhanced properties. Adv. Energy Mater. 8(1), 1701345 (2018). https://doi.org/10.1002/ aenm.201701345

96. Z. Geng, Y. Cao, W. Chen, X. Kong, Y. Liu, T. Yao, Y. Lin, Regulating the coordination environment of Co single atoms for achieving efficient electrocatalytic activity in $\mathrm{CO}_{2}$ reduction. Appl. Catal. B Environ. 240, 234-240 (2019). https:// doi.org/10.1016/j.apcatb.2018.08.075

97. S. Dou, C. Dong, Z. Hu, Y. Huang, J. Chen et al., Atomicscale $\mathrm{CoO}_{x}$ species in metal-organic frameworks for oxygen evolution reaction. Adv. Funct. Mater. 27(36), 1702546 (2017). https://doi.org/10.1002/adfm.201702546

98. L. Yang, L. Shi, D. Wang, Y. Lv, D. Cao, Single-atom cobalt electrocatalysts for foldable solid-state $\mathrm{Zn}$-air battery. Nano Energy 50, 691-698 (2018). https://doi.org/10.1016/j.nanoe n.2018.06.023

99. H.L. Fei, J.C. Dong, Y.X. Feng, C.S. Allen, C.Z. Wan et al., General synthesis and definitive structural identification of $\mathrm{MN}_{4} \mathrm{C}_{4}$ single-atom catalysts with tunable electrocatalytic activities. Nat. Catal. 1(1), 63-72 (2018). https://doi. org/10.1038/s41929-017-0008-y

100. P.Z. Chen, T.P. Zhou, L.L. Xing, K. Xu, Y. Tong et al., Atomically dispersed iron-nitrogen species as electrocatalysts for bifunctional oxygen evolution and reduction reactions. Angew. Chem. Int. Ed. 56(2), 610-614 (2017). https://doi. org/10.1002/anie.201610119

101. Q. Niu, B. Chen, J. Guo, J. Nie, X. Guo, G. Ma, Flexible, porous, and metal-heteroatom-doped carbon nanofibers as efficient ORR electrocatalysts for $\mathrm{Zn}$-air battery. NanoMicro Lett. 11, 8 (2019). https://doi.org/10.1007/s4082 0-019-0238-4

102. P. Yin, T. Yao, Y. Wu, L.R. Zheng, Y. Lin et al., Single cobalt atoms with precise $\mathrm{N}$-coordination as superior oxygen reduction reaction catalysts. Angew. Chem. Int. Ed. 55(36), 
10800-10805 (2016). https://doi.org/10.1002/anie.20160 4802

103. Y.J. Chen, S.F. Ji, Y.Y. Wang, J.C. Dong, W.X. Chen et al., Isolated single iron atoms anchored on $\mathrm{N}$-doped porous carbon as an efficient electrocatalyst for the oxygen reduction reaction. Angew. Chem. Int. Ed. 56(24), 6937-6941 (2017). https://doi.org/10.1002/anie.201702473

104. C. Zhao, X. Dai, T. Yao, W. Chen, X. Wang et al., Ionic exchange of metal-organic frameworks to access single nickel sites for efficient electroreduction of $\mathrm{CO}_{2}$. J. Am. Chem. Soc. 139(24), 8078-8081 (2017). https://doi.org/10.1021/ jacs.7b02736

105. B. Wang, X. Wang, J. Zou, Y. Yan, S. Xie, G. Hu, Y. Li, A. Dong, Simple-cubic carbon frameworks with atomically dispersed iron dopants toward high-efficiency oxygen reduction. Nano Lett. 17(3), 2003-2009 (2017). https://doi.org/10.1021/ acs.nanolett.7b00004

106. C. Zhang, J. Sha, H. Fei, M. Liu, S. Yazdi et al., Singleatomic ruthenium catalytic sites on nitrogen-doped graphene for oxygen reduction reaction in acidic medium. ACS Nano 11(7), 6930-6941 (2017). https://doi.org/10.1021/acsna no. $7 \mathrm{~b} 02148$

107. Y. Han, Y. Wang, W. Chen, R. Xu, L. Zheng et al., Hollow $\mathrm{N}$-doped carbon spheres with isolated cobalt single atomic sites: superior electrocatalysts for oxygen reduction. J. Am. Chem. Soc. 139(48), 17269-17272 (2017). https://doi. org/10.1021/jacs.7b10194

108. Z. Zhang, X. Gao, M. Dou, J. Ji, F. Wang, Biomass derived $\mathrm{N}$-doped porous carbon supported single Fe atoms as superior electrocatalysts for oxygen reduction. Small 13(22), 1604290 (2017). https://doi.org/10.1002/smll.201604290

109. C.W. Lee, K.D. Yang, D.H. Nam, J.H. Jang, N.H. Cho, S.W. Im, K.T. Nam, Defining a materials database for the design of copper binary alloy catalysts for electrochemical $\mathrm{CO}_{2}$ conversion. Adv. Mater. 30(42), 1704717 (2018). https://doi. org/10.1002/adma.201704717

110. M. Zhang, Q. Dai, H. Zheng, M. Chen, L. Dai, Novel MOFderived Co@N-C bifunctional catalysts for highly efficient $\mathrm{Zn}$-air batteries and water splitting. Adv. Mater. 30(10), 1705431 (2018). https://doi.org/10.1002/adma.201705431

111. Y. Wang, J. Liu, Y. Wang, A.M. Al-Enizi, G. Zheng, Tuning of $\mathrm{CO}_{2}$ reduction selectivity on metal electrocatalysts. Small 13(43), 1701809 (2017). https://doi.org/10.1002/smll.20170 1809

112. P. Song, M. Luo, X. Liu, W. Xing, W. Xu, Z. Jiang, L. Gu, $\mathrm{Zn}$ single atom catalyst for highly efficient oxygen reduction reaction. Adv. Funct. Mater. 27(28), 1700802 (2017). https ://doi.org/10.1002/adfm.201700802

113. Y.X. Duan, F.L. Meng, K.H. Liu, S.S. Yi, S.J. Li, J.M. Yan, Q. Jiang, Amorphizing of $\mathrm{Cu}$ nanoparticles toward highly efficient and robust electrocatalyst for $\mathrm{CO}_{2}$ reduction to liquid fuels with high faradaic efficiencies. Adv. Mater. 30(14), 1706194 (2018). https://doi.org/10.1002/adma.201706194

114. A. Vasileff, Y. Zheng, S.Z. Qiao, Carbon solving carbon's problems: recent progress of nanostructured carbonbased catalysts for the electrochemical reduction of $\mathrm{CO}_{2}$.
Adv. Energy Mater. 7(21), 1700759 (2017). https://doi. org/10.1002/aenm.201700759

115. W. Ju, A. Bagger, G.P. Hao, A.S. Varela, I. Sinev et al., Understanding activity and selectivity of metal-nitrogendoped carbon catalysts for electrochemical reduction of $\mathrm{CO}_{2}$. Nat. Commun. 8(1), 944 (2017). https://doi.org/10.1038/ s41467-017-01035-z

116. Y. Cao, Y. Gao, H. Zhou, X. Chen, H. Hu et al., Highly efficient ammonia synthesis electrocatalyst: single Ru atom on naturally nanoporous carbon materials. Adv. Theory Simul. 1(5), 1800018 (2018). https://doi.org/10.1002/adts.20180 0018

117. J. Zhao, Z. Chen, Single Mo atom supported on defective boron nitride monolayer as an efficient electrocatalyst for nitrogen fixation: a computational study. J. Am. Chem. Soc. 139(36), 12480-12487 (2017). https://doi.org/10.1021/ jacs.7b05213

118. C. Ling, X. Bai, Y. Ouyang, A. Du, J. Wang, Single molybdenum atom anchored on $\mathrm{N}$-doped carbon as a promising electrocatalyst for nitrogen reduction into ammonia at ambient conditions. J. Phys. Chem. C 122(29), 16842-16847 (2018). https://doi.org/10.1021/acs.jpcc.8b05257

119. H. Zhang, G. Liu, L. Shi, J. Ye, Single-atom catalysts: emerging multifunctional materials in heterogeneous catalysis. Adv. Energy Mater. 8(1), 1701343 (2018). https://doi.org/10.1002/ aenm.201701343

120. V. Vij, S. Sultan, A.M. Harzandi, A. Meena, J.N. Tiwari, W.-G. Lee, T. Yoon, K.S. Kim, Nickel-based electrocatalysts for energy-related applications: oxygen reduction, oxygen evolution, and hydrogen evolution reactions. ACS Catal. 7(10), 7196-7225 (2017). https://doi.org/10.1021/acsca tal.7b01800

121. X. Li, W. Bi, M. Chen, Y. Sun, H. Ju et al., Exclusive Ni-N sites realize near-unity $\mathrm{CO}$ selectivity for electrochemical $\mathrm{CO}_{2}$ reduction. J. Am. Chem. Soc. 139(42), 14889-14892 (2017). https://doi.org/10.1021/jacs.7b09074

122. D.J. Harding, C. Kerpal, G. Meijer, A. Fielicke, Activated methane on small cationic platinum clusters. Angew. Chem. Int. Ed. 51(3), 817-819 (2012). https://doi.org/10.1002/ anie. 201107042

123. J. Lin, A. Wang, B. Qiao, X. Liu, X. Yang et al., Remarkable performance of $\mathrm{Ir}_{1} / \mathrm{FeO}_{x}$ single-atom catalyst in water gas shift reaction. J. Am. Chem. Soc. 135(41), 15314-15317 (2013). https://doi.org/10.1021/ja408574m

124. Y. Chen, S. Ji, C. Chen, Q. Peng, D. Wang, Y. Li, Singleatom catalysts: synthetic strategies and electrochemical applications. Joule 2(7), 1242-1264 (2018). https://doi. org/10.1016/j.joule.2018.06.019

125. H. Wei, K. Huang, D. Wang, R. Zhang, B. Ge et al., Iced photochemical reduction to synthesize atomically dispersed metals by suppressing nanocrystal growth. Nat. Commun. 8(1), 1490 (2017). https://doi.org/10.1038/s41467-017-01521 $-4$

126. J. Yang, B. Chen, X. Liu, W. Liu, Z. Li et al., Efficient and robust hydrogen evolution: phosphorus nitride imide nanotubes as supports for anchoring single ruthenium sites. 
Angew. Chem. Int. Ed. 57(30), 9495-9500 (2018). https:// doi.org/10.1002/anie.201804854

127. Y. Qu, L. Wang, Z. Li, P. Li, Q. Zhang et al., Ambient synthesis of single-atom catalysts from bulk metal via trapping of atoms by surface dangling bonds. Adv. Mater. 31(44), 1904496 (2019). https://doi.org/10.1002/adma.201904496

128. B. Han, R. Lang, B. Qiao, A. Wang, T. Zhang, Highlights of the major progress in single-atom catalysis in 2015 and 2016. Chin. J. Catal. 38(9), 1498-1507 (2017). https://doi. org/10.1016/S1872-2067(17)62872-9

129. H. Wei, X. Liu, A. Wang, L. Zhang, B. Qiao et al., $\mathrm{FeO}_{x}$-supported platinum single-atom and pseudo-singleatom catalysts for chemoselective hydrogenation of functionalized nitroarenes. Nat. Commun. 5(1), 5634 (2014). https://doi.org/10.1038/ncomms6634

130. M. Moses-DeBusk, M. Yoon, L.F. Allard, D.R. Mullins, $\mathrm{Z}$. Wu et al., CO oxidation on supported single Pt atoms: experimental and ab initio density functional studies of $\mathrm{CO}$ interaction with $\mathrm{Pt}$ atom on $\theta-\mathrm{Al}_{2} \mathrm{O}_{3}(010)$ surface. J. Am. Chem. Soc. 135(34), 12634-12645 (2013). https://doi. org/10.1021/ja401847c

131. T.K. Ghosh, N.N. Nair, $\mathrm{Rh} 1 / \gamma-\mathrm{Al}_{2} \mathrm{O}_{3}$ single-atom catalysis of $\mathrm{O}_{2}$ activation and $\mathrm{CO}$ oxidation: mechanism, effects of hydration, oxidation state, and cluster size. ChemCatChem 5(7), 1811-1821 (2013). https://doi.org/10.1002/cctc.20120 0799

132. G. Spezzati, Y. Su, J.P. Hofmann, A.D. Benavidez, A.T. DeLaRiva, J. McCabe, A.K. Datye, E.J.M. Hensen, Atomically dispersed $\mathrm{Pd}-\mathrm{O}$ species on $\mathrm{CeO}_{2}(111)$ as highly active sites for low-temperature CO oxidation. ACS Catal. 7(10), 6887-6891 (2017). https://doi.org/10.1021/acscatal.7b020 01

133. J. Wan, W. Chen, C. Jia, L. Zheng, J. Dong et al., Defect effects on $\mathrm{TiO}_{2}$ nanosheets: stabilizing single atomic site $\mathrm{Au}$ and promoting catalytic properties. Adv. Mater. 30(11), 1705369 (2018). https://doi.org/10.1002/adma.201705369

134. B. Qiao, J. Liu, Y.-G. Wang, Q. Lin, X. Liu et al., Highly efficient catalysis of preferential oxidation of $\mathrm{CO}$ in $\mathrm{H}_{2}$-rich stream by gold single-atom catalysts. ACS Catal. 5(11), 6249-6254 (2015). https://doi.org/10.1021/acscatal.5b01114

135. B.J. O’Neill, D.H. Jackson, J. Lee, C. Canlas, P.C. Stair et al., Catalyst design with atomic layer deposition. ACS Catal. 5(3), 1804-1825 (2015). https://doi.org/10.1021/cs501862h

136. V. Aleskovsky, M. Koltcov, USSR Patent USSR422446 (1972)

137. S. Sun, G. Zhang, N. Gauquelin, N. Chen, J. Zhou et al., Single-atom catalysis using Pt/graphene achieved through atomic layer deposition. Sci. Rep. 3(5), 1775 (2013). https:// doi.org/10.1038/srep01775

138. H. Yan, H. Cheng, H. Yi, Y. Lin, T. Yao et al., Single-atom $\mathrm{Pd}_{1} /$ graphene catalyst achieved by atomic layer deposition: remarkable performance in selective hydrogenation of 1,3-butadiene. J. Am. Chem. Soc. 137(33), 10484-10487 (2015). https://doi.org/10.1021/jacs.5b06485

139. M.P. Hermida, Z. Lu, A. White, K.B. Low, T.P. Wu, J.W. Elam, Z.L. Wu, Y. Lei, Towards ALD thin film stabilized single-atom $\mathrm{Pd}_{1}$ catalysts. Nanoscale 8(33), 15348-15356 (2016). https://doi.org/10.1039/C6NR04403D

140. L. Zhang, Z. Zhao, M. Norouzi Banis, L. Li, Y. Zhao et al., Selective atomic layer deposition of $\mathrm{RuO}_{x}$ catalysts on shapecontrolled Pd nanocrystals with significantly enhanced hydrogen evolution activity. J. Mater. Chem. A 6(47), 24397-24406 (2018). https://doi.org/10.1039/c8ta08931k

141. S.J. Jeong, Y. Gu, J. Heo, J. Yang, C.S. Lee et al., Thickness scaling of atomic-layer-deposited $\mathrm{HfO}_{2}$ films and their application to wafer-scale graphene tunnelling transistors. Sci. Rep. 6(10), 20907 (2016). https://doi.org/10.1038/srep2 0907

142. M. Leskela, M. Ritala, Atomic layer deposition chemistry: recent developments and future challenges. Angew. Chem. Int. Ed. 42(45), 5548-5554 (2003). https://doi.org/10.1002/ anie. 200301652

143. H. Kim, J. Vac, Atomic layer deposition of metal and nitride thin films: current research efforts and applications for semiconductor device processing. Sci. Technol. B 21(6), 22312261 (2003). https://doi.org/10.1116/1.162267

144. R.J. Kuppler, D.J. Timmons, Q. Fang, J. Li, T.A. Makal et al., Potential applications of metal-organic frameworks. Coord. Chem. Rev. 253(23-24), 3042-3066 (2009). https://doi. org/10.1016/j.ccr.2009.05.019

145. H. Furukawa, K.E. Cordova, M. O'Keeffe, O.M. Yaghi, The chemistry and applications of metal-organic frameworks. Science 341(6149), 1230444 (2013). https://doi.org/10.1126/ science. 1230444

146. A.J. Howarth, Y. Liu, P. Li, Z. Li, T.C. Wang, J.T. Hupp, O.K. Farha, Chemical, thermal and mechanical stabilities of metal-organic frameworks. Nat. Rev. Mater. 1, 15018 (2016). https://doi.org/10.1038/natrevmats.2015.18

147. X. Wang, Z. Chen, X. Zhao, T. Yao, W. Chen et al., Regulation of coordination number over single Co sites: triggering the efficient electroreduction of $\mathrm{CO}_{2}$. Angew. Chem. Int. Ed. 57(7), 1944-1948 (2018). https://doi.org/10.1002/anie.20171 2451

148. W. Chen, J. Pei, C. He, J. Wan, H. Ren et al., Single tungsten atoms supported on MOF-derived N-doped carbon for robust electrochemical hydrogen evolution. Adv. Mater. 30(30), 1800396 (2018). https://doi.org/10.1002/adma.201800396

149. Y. Pan, R. Lin, Y. Chen, S. Liu, W. Zhu et al., Design of single-atom $\mathrm{Co}-\mathrm{N}_{5}$ catalytic site: a robust electrocatalyst for $\mathrm{CO}_{2}$ reduction with nearly $100 \% \mathrm{CO}$ selectivity and remarkable stability. J. Am. Chem. Soc. 140(12), 4218-4221 (2018). https://doi.org/10.1021/jacs.8b00814

150. J. Wang, Z. Huang, W. Liu, C. Chang, H. Tang et al., Design of $\mathrm{N}$-coordinated dual-metal sites: a stable and active Pt-free catalyst for acidic oxygen reduction reaction. J. Am. Chem. Soc. 139(48), 17281-17284 (2017). https://doi.org/10.1021/ jacs.7b10385

151. S. Ji, Y. Chen, Q. Fu, Y. Chen, J. Dong et al., Confined pyrolysis within metal-organic frameworks to form uniform $\mathrm{Ru}_{3}$ clusters for efficient oxidation of alcohols. J. Am. Chem. 
Soc. 139(29), 9795-9798 (2017). https://doi.org/10.1021/ jacs.7b05018

152. X. Wang, W. Chen, L. Zhang, T. Yao, W. Liu et al., Uncoordinated amine groups of metal-organic frameworks to anchor single $\mathrm{Ru}$ sites as chemoselective catalysts toward the hydrogenation of quinoline. J. Am. Chem. Soc. 139(28), 9419-9422 (2017). https://doi.org/10.1021/jacs.7b01686

153. W. Chen, J. Pei, C. He, J. Wan, H. Ren et al., Rational design of single molybdenum atoms anchored on $\mathrm{N}$-doped carbon for effective hydrogen evolution reaction. Angew. Chem. Int. Ed. 56(50), 16086-16090 (2017). https://doi.org/10.1002/ anie. 201710599

154. G. Dong, M. Fang, H. Wang, S. Yip, H.-Y. Cheung et al., Insight into the electrochemical activation of carbon-based cathodes for hydrogen evolution reaction. J. Mater. Chem. A 3(24), 13080-13086 (2015). https://doi.org/10.1039/C5TA0 $2551 \mathrm{~F}$

155. Y. Xue, B. Huang, Y. Yi, Y. Guo, Z. Zuo et al., Anchoring zero valence single atoms of nickel and iron on graphdiyne for hydrogen evolution. Nat. Commun. 9(1), 1460 (2018). https://doi.org/10.1038/s41467-018-03896-4

156. J. Jones, H. Xiong, A.T. DeLaRiva, E.J. Peterson, H. Pham et al., Thermally stable single-atom platinum-on-ceria catalysts via atom trapping. Science 353(6295), 150-154 (2016). https://doi.org/10.1126/science.aaf8800

157. S. Wei, A. Li, J. Liu, Z. Li, W. Chen et al., Direct observation of noble metal nanoparticles transforming to thermally stable single atoms. Nat. Nanotechnol. 13(9), 856-861 (2018). https ://doi.org/10.1038/s41565-018-0197-9

158. J. Yang, Z. Qiu, C. Zhao, W. Wei, W. Chen et al., In situ thermal atomization to convert supported nickel nanoparticles into surface-bound nickel single-atom catalysts. Angew. Chem. Int. Ed. 57(43), 14095-14100 (2018). https://doi. org/10.1002/anie.201808049

159. Y. Qu, Z. Li, W. Chen, Y. Lin, T. Yuan et al., Direct transformation of bulk copper into copper single sites via emitting and trapping of atoms. Nat. Catal. 1, 781-786 (2018). https ://doi.org/10.1038/s41929-018-0146-x

160. Y. Qu, B. Chen, Z. Li, X. Duan, L. Wang et al., Thermal emitting strategy to synthesize atomically dispersed Pt metal sites from bulk Pt metal. J. Am. Chem. Soc. 141(11), 4505-4509 (2019). https://doi.org/10.1021/jacs.8b09834

161. J. Zhang, Y. Zhao, X. Guo, C. Chen, C. Dong et al., Single platinum atoms immobilized on an MXene as an efficient catalyst for the hydrogen evolution reaction. Nat. Catal. 1, 985-992 (2018). https://doi.org/10.1038/s41929-018-0195-1

162. D. Zhao, Z. Chen, W. Yang, S. Liu, X. Zhang et al., MXene $\left(\mathrm{Ti}_{3} \mathrm{C}_{2}\right)$ vacancy-confined single-atom catalyst for efficient functionalization of $\mathrm{CO}_{2}$. J. Am. Chem. Soc. 141(8), 40864093 (2019). https://doi.org/10.1021/jacs.8b13579

163. J. Zhang, X. Wu, W.-C. Cheong, W. Chen, R. Lin et al., Cation vacancy stabilization of single-atomic-site $\mathrm{Pt}_{1} / \mathrm{Ni}(\mathrm{OH})_{x}$ catalyst for diboration of alkynes and alkenes. Nat. Commun. 9(1), 1002 (2018). https://doi.org/10.1038/s41467-018-03380 $-\mathrm{z}$
164. X. Li, J. Yu, J. Jia, A. Wang, L. Zhao, T. Xiong, H. Liu, W. Zhou, Confined distribution of platinum clusters on $\mathrm{MoO}_{2}$ hexagonal nanosheets with oxygen vacancies as a high-efficiency electrocatalyst for hydrogen evolution reaction. Nano Energy 62, 127-135 (2019). https://doi.org/10.1016/j.nanoe n.2019.05.013

165. Y. Wang, Z. Chen, P. Han, Y. Du, Z. Gu, X. Xu, G. Zheng, Single-atomic $\mathrm{Cu}$ with multiple oxygen vacancies on ceria for electrocatalytic $\mathrm{CO}_{2}$ reduction to $\mathrm{CH}_{4}$. ACS Catal. 8(8), 7113-7119 (2018). https://doi.org/10.1021/acscatal.8b01014

166. D. Deng, X. Chen, L. Yu, X. Wu, Q. Liu et al., A single iron site confined in a graphene matrix for the catalytic oxidation of benzene at room temperature. Sci Adv. 1(11), 1500462 (2015). https://doi.org/10.1126/sciadv.1500462

167. J.H. Kwak, J. Hu, D. Mei, C.W. Yi, D.H. Kim, C. Peden, H.L. Allard, J. Szanyi, Coordinatively unsaturated $\mathrm{Al}^{3+}$ centers as binding sites for active catalyst phases of platinum on gamma- $\mathrm{Al}_{2} \mathrm{O}_{3}$. Science 325(5948), 1670-1673 (2009). https ://doi.org/10.1126/science.1176745

168. A. Corma, O.G. Salnikov, D.A. Barskiy, K.V. Kovtunov, I.V. Koptyug, Single-atom gold catalysis in the context of developments in parahydrogen-induced polarization. Chem. Eur. J. 21(19), 7012-7015 (2015). https://doi.org/10.1002/ chem. 201406664

169. J. Ryczkowski, IR spectroscopy in catalysis. Catal. Today 68(4), 263-381 (2001). https://doi.org/10.1016/S0920 $-5861(01) 00334-0$

170. C. Lamberti, A. Zecchina, E. Groppo, S. Bordiga, Probing the surfaces of heterogeneous catalysts by in situ IR spectroscopy. Chem. Soc. Rev. 39(12), 4951-5001 (2010). https ://doi.org/10.1039/C0CS00117A

171. Y. Zhou, G. Gao, Y. Li, W. Chu, L. Wang, Transitionmetal single atoms in nitrogen-doped graphenes as efficient active centers for water splitting: a theoretical study. Phys. Chem. Chem. Phys. 21(6), 3024-3032 (2019). https://doi. org/10.1039/C8CP06755D

172. C. Ling, L. Shi, Y. Ouyang, X. Zeng, J. Wang, Nanosheet supported single-metal atom bifunctional catalyst for overall water splitting. Nano Lett. 17(8), 5133-5139 (2017). https:// doi.org/10.1021/acs.nanolett.7b02518

173. Z. Geng, Y. Liu, X. Kong, P. Li, K. Li et al., Achieving a record-high yield rate of $120.9 \mathrm{\mu g} \mathrm{NH}_{3} \mathrm{mg}_{\text {cat }}{ }^{-1} \mathrm{~h}^{-1}$ for $\mathrm{N}_{2}$ electrochemical reduction over $\mathrm{Ru}$ single-atom catalysts. Adv. Mater. 30(40), 1803498 (2018). https://doi.org/10.1002/ adma.201803498

174. K. Mori, T. Taga, H. Yamashita, Isolated single-atomic Ru catalyst bound on a layered double hydroxide for hydrogenation of $\mathrm{CO}_{2}$ to formic acid. ACS Catal. 7(5), 3147-3151 (2017). https://doi.org/10.1021/acscatal.7b00312

175. H. Zhang, P. An, W. Zhou, B.Y. Guan, P. Zhang, J. Dong, X.W. Lou, Dynamic traction of lattice-confined platinum atoms into mesoporous carbon matrix for hydrogen evolution reaction. Sci. Adv. 4(1), eaao6657 (2018). https://doi. org/10.1126/sciadv.aao6657

176. X. Yin, H. Wang, S. Tang, X. Lu, M. Shu, R. Si, T. Lu, Engineering the coordination environment of single-atom 
platinum anchored on graphdiyne for optimizing electrocatalytic hydrogen evolution. Angew. Chem. Int. Ed. 57(30), 9382-9386 (2018). https://doi.org/10.1002/anie.201804817

177. Z. Luo, Y. Ouyang, H. Zhang, M. Xiao, J. Ge et al., Chemically activating $\mathrm{MoS}_{2}$ via spontaneous atomic palladium interfacial doping towards efficient hydrogen evolution. Nat. Commun. 9(1), 2120 (2018). https://doi.org/10.1038/s4146 7-018-04501-4

178. Y. Guan, Y. Feng, J. Wan, X. Yang, L. Fang et al., Ganoderma-like $\mathrm{MoS}_{2} / \mathrm{NiS}_{2}$ with single platinum atoms doping as an efficient and stable hydrogen evolution reaction catalyst. Small 14(27), 1800697 (2018). https://doi.org/10.1002/ smll.201800697

179. L. Fan, P. Liu, X. Yan, L. Gu, Z. Yang, H. Yang, S. Qiu, $\mathrm{X}$. Yao, Atomically isolated nickel species anchored on graphitized carbon for efficient hydrogen evolution electrocatalysis. Nat. Commun. 7, 10667 (2016). https://doi.org/10.1038/ ncomms 10667

180. H. Qiu, Y. Ito, W. Cong, Y. Tan, P. Liu et al., Nanoporous graphene with single-atom nickel dopants: an efficient and stable catalyst for electrochemical hydrogen production. Angew. Chem. Int. Ed. 54(47), 14031-14035 (2015). https ://doi.org/10.1002/anie.201507381

181. C. Zhang, S. Yang, J. Wu, M. Liu, S. Yazdi et al., Electrochemical $\mathrm{CO}_{2}$ reduction with atomic iron-dispersed on nitrogen-doped graphene. Adv. Energy Mater. 8(19), 1703487 (2018). https://doi.org/10.1002/aenm.201703487

182. L. Cao, Q. Luo, W. Liu, Y. Lin, X. Liu et al., Identification of single-atom active sites in carbon-based cobalt catalysts during electrocatalytic hydrogen evolution. Nat. Catal. 2, 134-141 (2019). https://doi.org/10.1038/s41929-018-0203-5

183. T. He, C. Zhang, A. Du, Single-atom supported on graphene grain boundary as an efficient electrocatalyst for hydrogen evolution reaction. Chem. Eng. Sci. 194, 58-63 (2019). https ://doi.org/10.1016/j.ces.2018.03.028

184. L. Zhang, Y. Jia, G. Gao, X. Yan, N. Chen et al., Graphene defects trap atomic Ni species for hydrogen and oxygen evolution reactions. Chem 4(2), 285-297 (2018). https://doi. org/10.1016/j.chempr.2017.12.005

185. W. Liu, Q. Xu, P. Yan, J. Chen, Y. Du, S. Chu, J. Wang, Fabrication of a single-atom platinum catalyst for the hydrogen evolution reaction: a new protocol by utilization of $\mathrm{H}_{x} \mathrm{MoO}_{3-x}$ with plasmon resonance. ChemCatChem 10(5), 946-950 (2018). https://doi.org/10.1002/cctc.201701777

186. S. Ye, F. Luo, Q. Zhang, P. Zhang, T. Xu et al., Highly stable single Pt atomic sites anchored on aniline-stacked graphene for hydrogen evolution reaction. Energy Environ. Sci. 12(3), 1000-1007 (2019). https://doi.org/10.1039/C8EE02888E

187. M. Li, K. Duanmu, C. Wan, T. Cheng, L. Zhang et al., Single-atom tailoring of platinum nanocatalysts for highperformance multifunctional electrocatalysis. Nat. Catal. 2, 495-503 (2019). https://doi.org/10.1038/s41929-019-0279-6

188. H. Wei, H. Wu, K. Huang, B. Ge, J. Ma et al., Ultralowtemperature photochemical synthesis of atomically dispersed $\mathrm{Pt}$ catalysts for the hydrogen evolution reaction. Chem. Sci. 10(9), 2830-2836 (2019). https://doi.org/10.1039/C8SC0 $4986 \mathrm{~F}$

189. K. Jiang, B. Liu, M. Luo, S. Ning, M. Peng et al., Single platinum atoms embedded in nanoporous cobalt selenide as electrocatalyst for accelerating hydrogen evolution reaction. Nat. Commun. 10, 1743 (2019). https://doi.org/10.1038/ s41467-019-09765-y

190. T. Chao, X. Luo, W. Chen, B. Jiang, J. Ge et al., Atomically dispersed copper-platinum dual sites alloyed with palladium nanorings catalyze the hydrogen evolution reaction. Angew. Chem. Int. Ed. 56(50), 16047-16051 (2017). https://doi. org/10.1002/anie.201709803

191. S. Yuan, Z. Pu, H. Zhou, J. Yu, I.S. Amiinu et al., A universal synthesis strategy for single atom dispersed cobalt/metal clusters heterostructure boosting hydrogen evolution catalysis at all pH values. Nano Energy 59, 472-480 (2019). https:// doi.org/10.1016/j.nanoen.2019.02.062

192. D. Wang, Q. Li, C. Han, Z. Xing, X. Yang, Single-atom ruthenium based catalyst for enhanced hydrogen evolution. Appl. Catal. B Environ. 249, 91-97 (2019). https://doi. org/10.1016/j.apcatb.2019.02.059

193. L. Zhang, R. Si, H. Liu, N. Chen, Q. Wang et al., Atomic layer deposited Pt-Ru dual-metal dimers and identifying their active sites for hydrogen evolution reaction. Nat. Commun. 10, 4936 (2019). https://doi.org/10.1038/s41467-019-12887 $-\mathrm{y}$

194. Y. Zhao, T. Ling, S. Chen, B. Jin, A. Vasileff et al., Non-metal single-iodine-atom electrocatalysts for the hydrogen evolution reaction. Angew. Chem. Int. Ed. 58(35), 12252-12257 (2019). https://doi.org/10.1002/anie.201905554

195. J. Yi, R. Xu, G. Chai, T. Zhang, K. Zang et al., Cobalt singleatoms anchored on porphyrinic triazine-based frameworks as bifunctional electrocatalysts for oxygen reduction and hydrogen evolution reactions. J. Mater. Chem. A 7, 1252-1259 (2019). https://doi.org/10.1039/C8TA09490J 